\begin{tabular}{|l|l|}
\hline $\begin{array}{l}\text { 2. To: (Receiving Organization) } \\
\text { Distribution }\end{array}$ & $\begin{array}{l}\text { 3. From: (Originating Organization) } \\
\text { Plutonium Fini shing Plant }\end{array}$ \\
\hline $\begin{array}{l}\text { 5. Proj./Prog./Dept./Dw.: } \\
\text { PFP Prog. Mgmt. }\end{array}$ & $\begin{array}{l}\text { 6. Design Authority/Design Agent/Cog. Engr. } \\
\text { J. C. Sinc] a ir I I I }\end{array}$ \\
\hline
\end{tabular}

8. Originator Remarks:

For approval and release.

4. Related EDT No.:

626775 thru 626783

7. Purchase Order No.:

$\mathrm{N} / \mathrm{A}$

9. Equip./Component No.:

$\mathrm{N} / \mathrm{A}$

10. System/Bldg.JFacility:

$\mathrm{N} / \mathrm{A}$

12. Major Assm. Dwg. No.:

$\mathrm{N} / \mathrm{A}$

13. Permit/Permit Application No.:

$\mathrm{N} / \mathrm{A}$

14. Required Response Date:

N/A

15.

\begin{tabular}{|l|c|}
\hline $\begin{array}{c}\text { (A) } \\
\text { Item } \\
\text { No. }\end{array}$ & (B) Document/Drawing No. \\
\hline 1 & HNF-3725 \\
\hline & \\
\hline & \\
\hline & \\
\hline & \\
\hline & \\
\hline
\end{tabular}

16.

\begin{tabular}{|c|}
\hline Approval Designator (F) \\
\hline E, S, Q, D OR N/A \\
(See WHC-CM-3-5, \\
Sec. 12.7) \\
\hline
\end{tabular}

17.

Rea-

som

$+$

11. Receiver Remarks:

11A. Design Baseline Document? O Yes O No

DATA TRANSMITTED No.

Planning Guide

KEY

Reason for Transmittal (G)

4. Review

1. Approval

3. Information

5. Post-Review

6. Dist. (Receipt Acknow. Required)

SIGNATUREIDISTRIBUTION

(See Approval Designator for required signatures)

(K) Signature

21 Cog. Mgr. J.C. Sinclai, III

(C) Sheet (D) Rev. (E) Tttle or Description of Data Transmitted

$0 \quad$ PFP Issues/Assumptions

Development and Management

\begin{tabular}{|c|c|c|c|}
\hline (F) & (G) & (H) & (I) \\
\hline $\begin{array}{c}\text { Approval } \\
\text { besig- } \\
\text { nator }\end{array}$ & $\begin{array}{c}\text { Reason } \\
\text { for Trans- } \\
\text { mittal }\end{array}$ & $\begin{array}{c}\text { Origi- } \\
\text { nator } \\
\text { Dispo- } \\
\text { stion }\end{array}$ & $\begin{array}{c}\text { Receiv- } \\
\text { er } \\
\text { Dispo- } \\
\text { sition }\end{array}$ \\
\hline n/a & 2 & 1 & \\
\hline & & & \\
\hline & & & \\
\hline & & & \\
\hline & & & \\
\hline
\end{tabular}

Dispositton (H) \& (I)

1. Approved

2. Approved w/comment

3. Disapproved w/comment

4. Reviewed no/comment

5. Reviewed w/comment

6. Receipt acknowledged

\begin{tabular}{ll|l|l|llll|} 
(L) Date (M) MSIN & $\begin{array}{c}\text { Rea- } \\
\text { son }\end{array}$ & $\begin{array}{c}\text { (H) } \\
\text { Disp. }\end{array}$ & (J) Name & (K) Signature & (L) Date & (M) MSIN \\
\hline
\end{tabular}

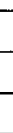

R. M. Millikin

L5-65

Design Agent

$1 \quad 1$ Cog. Eng. J.C. Sinclair-II

QA

T5-50

Safety

Eny.
18.

Ronllll.

Signature of EDT

Originator
R.M. Millikin.

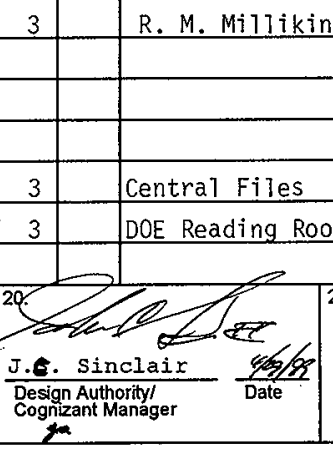

J.6. Sinclair Authorized Representative for Receiving Organization Ra

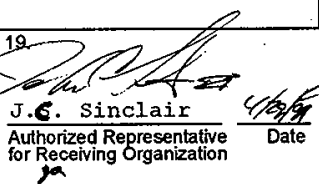

Date
Bl -07

$\mathrm{H} 2-53$

BD-7400-172-2 (10/97)
Ctrl No.

Approved

Approved w/comments

Disapproved w/comments 


\title{
PFP Issues/Assumptions Development and Management Planning Guide
}

\author{
J.C. Sinclair \\ B\&W Hanford Company \\ Richland, WA 99352 \\ U.S. Department of Energy Contract DE-AC06-96RL13200

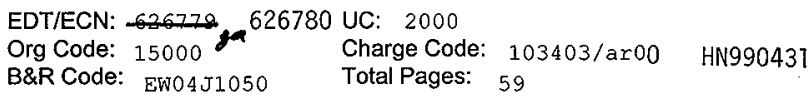

Key Words: PFP, Issues, Assumptions, Planning Assumptions, Technical Issues Managment Iist

Abstract: This document includes the planning guide used for the development of the PFP issues and assumptions managment list. The PFP life-cycle project was re-baselined in FY99. The PFP life-cycle baseline is documented in the Integrated PRoject Management Plan for the Plutonium Finishing Plant Stabilization and Deactivation Project, HNF-3617.

TRADEMARK DISCLAIMER. Reference herein to any specific commercial product, process, or service by trade name, trademark, manufacturer, or otherwise, does not necessarily constitute or imply its endorsement, recommendation, or favoring by the United States Government or any agency thereof or its contractors or subcontractors.

Printed in the United States of America. To obtain copies of this document, contact: Document Control Services, P.O. Box 950, Mailstop H6-08, Richland WA 99352, Phone (509) 372-2420; Fax (509) 376-4989.

$\frac{\text { Ramis Aandal }}{\text { Lelease Approval }} \frac{5-6-99}{\text { Date }}$

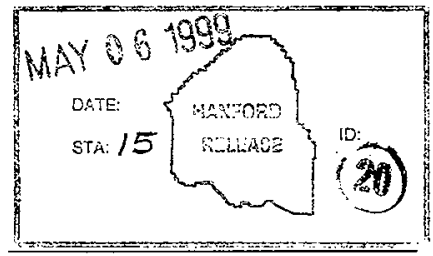

Release Stamp 


\section{PFP Issues/Assumptions Development and Management Planning Guide}

HNF-3725, Rev. 0

Prepared by

B\&W Hanford Company and Fluor Daniel Hanford, Inc.

Prepared for

U.S. Department of Energy, Richland Operations Office 


\section{Table of Contents}

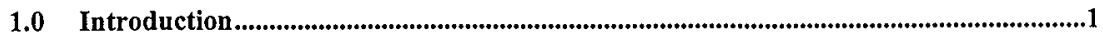

$2.0 \quad$ Statement of Need .......................................................................................................................

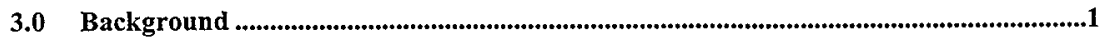

4.0 Definitions .....................................................................................................................................2

5.0 Issues/Assumptions Development and Maintenance Approach ..........................................3

5.1 Issues/Assumptions Development Documentation .......................................................... 3

5.2 Issues/Assumptions List Maintenance Approach ...........................................................4

5.3 Issue Identification, Assignment, Categorization and Closure .....................................4

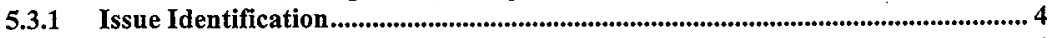

5.3.2 Responsibility Assignment .......................................................................................... 4

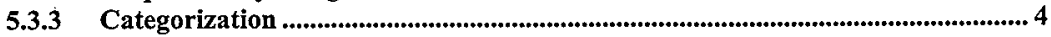

5.3.4 Issue Closure.............................................................................................................. 5

5.4 Data Elements Associated with Technical Issues............................................................... 5

5.4.1 Required Data: .................................................................................................................. 5

5.5 Duties and Expectations of Personnel Identified with Issues ........................................ 6

5.5.1 Issue Resolution.......................................................................................................... 6

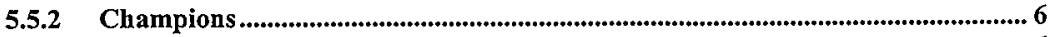

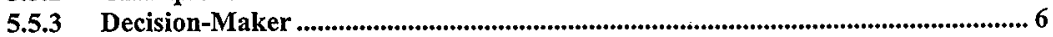

5.6 Technical Issues Management List Maintenance ............................................................. 7

5.6.1 Closed Issues............................................................................................................... 7

5.6.2 Technical Issues Management List Publication ....................................................... 7

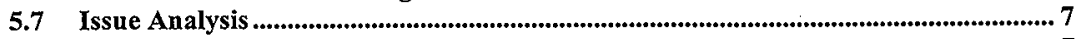

5.8 Issue Prioritization ............................................................................................................ 7

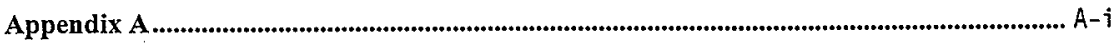

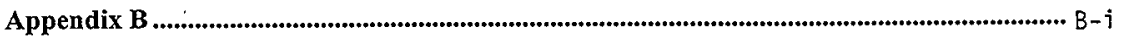




\subsection{Introduction}

The PFP Issues/Assumptions Development and Management Planning Guide presents the strategy and process used for the identification, allocation, and maintenance of an Issues/Assumptions Management List for the Plutonium Finishing Plant (PFP) integrated project baseline. Revisions to this document will include, as attachments, the most recent version of the Issues/Assumptions Management List, both open and current issues/assumptions (Appendix A), and closed or historical issues/assumptions (Appendix B).

This document is intended be a Project-owned management tool. As such, this document will periodically require revisions resulting from improvements of the information, processes, and techniques as now described. Revisions that suggest improved processes will only require PFP management approval.

\subsection{Statement of Need}

To complete the implementation of the overall Systems Engineering/Project Management Modified Approach to the development of the upgraded and accelerated PFP project baseline, a thorough analysis of project-related issues and assumptions is required. A complete and working Issues and Assumptions Management List will ensure that the PFP baseline maintains a high confidence level and that the uncertainty associated with a system function or work breakdown structure activity is actively being managed to reduce the overall potential impact on the project schedule. This planning guide has been developed to be consistent with the requirements of the site procedure, HNF-PRO-419, Technical Issues Management List Procedure.

\subsection{Background}

The PFP Stabilization and Deactivation Project's (hereafter referred to as the Project) schedule has many areas of uncertainty due to changing requirements, first-of-a-kind processing, packaging long-lead procurements currently in the conceptual or specification stage, and years of operations which have on occasion included upsets and contained spilis and leaks. Implementation of an issues management program, which addresses project and subproject issues, is a key element in managing risks to the Project's integrated baseline. Disciplined risk management is required to ensure that the accelerated PFP schedule does not result in undue safety, environmental, technical, schedule, nor financial risks. As such, an issue and assumptions identification, development, and management tool is required to effectively manage the project risk and uncertainty associated with the baseline. Issues and/or assumptions originate from a variety of sources and require different actions for resolution. 


\subsection{Definitions}

The following provides the reader and the reviewer of the planning guides used in the development of the PFP Integrated Project Management Plan with common terms and their definitions:

Activity-Based Cost Estimate - An activity-based cost (ABC) estimate is prepared at the lowest practical level in the work breakdown structure (functional breakdown) where labor, equipment, and material costs can be defined for the activity.

Integrated Baseline - The interrelated aspects of the technical scope, project schedule, and activity-based cost estimate make up the Integrated Baseline. Key elements of the Project's Integrated Baseline will be documented electronically in the Technical Baseline Management System. Key baseline elements, which will be maintained electronically, include work breakdown structure and dictionary (e.g., functions and functional analysis), requirements, issues/assumptions, interfaces, location descriptions, basis of estimate, schedule information, milestones, and requirements closure criteria.

Functional Analysis - The Functional Analysis defines what the system must do (i.e., the activities or "functions") to achieve the overall objectives (mission) and defines the internal and external interactions among the activities. The Functional Analysis is the basis for the Project's technical logic, work breakdown structure, definition of subprojects, the organization structure, the Project's files, process flow diagrams, and definition of the Project's Technical Baseline.

Requirements Analysis - The Requirements Analysis consists of the identification of the applicable requirements. This analysis results in the Project's requirements baseline, which is the foundation for identifying the activities, which will satisfy these requirements (the functional analysis). All requirements must be allocated to the individual functions or elements of the system. Requirements will be maintained in the Technical Baseline Management System, as an integral part of the Project's Technical Baseline.

Systems Engineering/Project Management Modified Approach - The Systems Engineering/Project Management Modified Approach is a focused accelerated effort undertaken to develop the upgraded PFP project baseline. The approach uses the fundamental concepts of systems engineering, combined with the rigor of sound project management principles, to establish a defensible and traceable requirements-based Technical Baseline.

Technical Baseline - The Technical Baseline is the body of technical information associated with the personnel, the processes, and the products required to accomplish the Project's mission. The initial Technical Baseline is a formal description of functions (activities), their sequence and interactions, and the requirements and constraints needed to define the system. The Technical Baseline also provides the basis to develop cost estimates and schedules used for management of work. A Technical Baseline may evolve over the Project's life cycle from a Requirements Baseline, through a Design Baseline, an As-built Baseline, an Operational Baseline, and a Deactivation Baseline. 
Issue - An issue is an area of uncertainty. The level of uncertainty tracked and described as an issue should be at the project managers discretion based on the relative level of risk to the project and authority the project manager has to manage the uncertainty. Each issue is assigned to a specific organization (manager) for resolution.

Assumption - An assumption is a supposition that should be used in the case where a rule or a fact has changed in the past or can potentially change in the future. An assumption should only be documented and tracked if a change in the rule or fact would change the baseline.

Enabling Assumption - An issue that results in an assumption that allows (enables) the planning to continue until the issue is resolved is an enabling assumption. This enabling assumption is a statement of the most reasonable or likely path forward on an issue and/or area of project uncertainty.

Issue/Assumptions Resolution Action Type - An Issue/Assumptions Resolution Action Type is a tool to be used for the resolution of the area of uncertainty. Standard tools to be used in the development of the PFP baseline will include (but not be limited to): workshops, trade/engineering studies, memorandum of agreement, acquisitions, and technical work plans. Documentation of closure of each issue is an important final step in the process.

\subsection{Issues/Assumptions Development and Maintenance Approach}

The process described below will be used to develop and maintain the Issues/Assumption Management List during the development of the PFP project baseline.

\subsection{Issues/Assumptions Development Documentation}

The approach for assembly of project issues, assumptions, at all levels of the functional history includes the collection and review of existing PFP and Hanford Site documentation. As documents are reviewed, assessments are made to determine if they are valid sources of project issues, assumptions, and/or enabling assumptions. If issues and assumptions are extracted from these documents, the Issues/Assumptions Management List is to contain the source document as a reference. In addition, notes from workshops and other project related meetings conducted during the development of the PFP baseline are to be evaluated as sources of issues and assumptions.

As the Functional and Requirements Analyses are being developed, special templates are used that include cells for listing issues and assumptions based on a given function or requirement. These issues/assumptions are mapped to the given function (work breakdown structure element). Issues/Assumptions gathered from source documents are to be mapped to the appropriate function upon completion of the Functional Analysis. Finally, issues and assumptions are to be documented through reviews and by interviews with project representatives and management. 


\subsection{Issues/Assumptions List Maintenance Approach}

During the development of the PFP baseline, the Issues and Assumptions Management List was maintained and revised as an appendix to this document. Items were added to the list by the baseline development team (PFP Tiger Team A) from the baseline development effort or through direction from the PFP. This Issues and Assumptions Management List was provided to the issues management team (PFP Tiger Team B) on a weekly basis for action and interface with PFP. Items will not be deleted from the list but will be statused as open or closed. Open issues at the time the baseline is submitted will be accompanied by an enabling assumption within the baseline.

An electronic database with issues and assumptions mapped to the functions is to be provided to PFP at the conclusion of the baseline development process for maintenance and resolution.

\subsection{Issue Identification, Assignment, Categorization and Closure}

\subsubsection{Issue Identification}

An issue results from missing data required for planning or execution of an activity. This may be a requirement or function that has not been defined, an architecture that has not been identified, or the inability of a project to meet previously defined requirements for any of a number of reasons. Each issue results in a planning assumption that is used until the issue is resolved. Issues can be identified by any member of the Project management or staff.

\subsubsection{Responsibility Assignment}

Once identified, an issue is reviewed for inclusion in the Technical Issues Management List by Project management. Management assigns a champion to manage resolution of the issue. The duties of the champion are described in Section 5.5.

\subsubsection{Categorization}

An issue is placed in one of three categories:

Category 1 Issues: Technical issues that lie within the scope and responsibility of the PFP Project to resolve. The deliverable from the resolution of these issues will be a decision and resultant baseline change, if required.

Category 2 Issues: Technical issues that are beyond the scope and responsibility of the PFP Project to resolve, but within the scope and responsibility of Hanford to resolve. These issues will be carried as planning assumptions in the Project baseline until the resolved within Hanford.

Category 3 Issues: Technical issues beyond the scope and responsibility of Hanford to resolve. These issues will be carried as planning assumptions in the Project baseline until the off-site decision authority resolves the issue. 


\subsubsection{Issue Closure}

An issue will be considered closed when the proper approved authorities have formally documented a decision, and activities necessary to implement the decision are scheduled and funded in the baseline. The Technical Issues Management List will be modified to status the issue as closed, and to reflect the closure documentation.

\subsection{Data Elements Associated with Technical Issues}

Specific data is to be developed for each technical issue. Supporting data and documentation relating to resolution of an issue shall be maintained in a file unique to that issue.

\subsubsection{Required Data:}

The required data is entered into the Technical Baseline Management System database (TBMS). Appendix A is a query from that database. The identifiers for the required data are based on the Technical Issues Management List, HNF-PRO-419, Rev 0. Some of the following identifiers were modified for inclusion in the TBMS, and these modifications are indicated in parenthesis ():

a. Issue Number (Assumption/Issues Management ID): A unique number will be assigned to each issue. The number will never be reused.

b. Issue Type (Assumption/Issue Type): Planning or Issue.

c. Issue (Title): A descriptive title followed by a concise description of the substance of the issue.

d. Affected Elements (WBS Number and WBS Title): Any internal or external functional or organization interfaces affected by the issue and its resolution.

e. Required Decision (Description): A concise description of the action required from the decision-maker to resolve the issue

f. Planning Assumption (Source): A concise summary of the planning assumption to be used until the issue is resolved.

g. Impact (General Description): A brief description of the consequences of the decision being different from the planning assumption, or of the decision not being made in the required time frame.

h. Action Type: Describes the action required to resolve the issue, such as generation of a Memorandum of Understanding, completion of a trade study, acquiring a new system, etc.

i. Source (Document Title): The documented source of the issue.

j. Category: See Section 5.3.3 for a description of categories.

k. Recommendation Date (Start): The date that the recommended resolution to the issue must be delivered to the Project decision-makers.

1. Decision Date (Finish): The date that the decision must be made for Category 1 issues, or the planning assumption must be approved for Category 2 and 3 issues in order to maintain the approved baseline.

m. Status: Open or closed. If open, provide a brief summary of progress. 
n. Champions: The names and titles of those individuals at all levels who are responsible for resolution of the issue. Must include issue resolution lead.

o. Decision Maker: The individual within the Project, at Hanford, or external to Hanford who must make the decisions which will resolve the issue.

\subsection{Duties and Expectations of Personnel Identified with Issues}

\subsubsection{Issue Resolution}

The primary responsibility of the leader is to deliver the recommended resolution of the issue to the decision-maker on schedule. Other duties may include:

a. Identify and coordinate with organizations affected by the issue.

b. Clearly define the issue and ensure it is correctly described in the Technical Issues Management List.

c. Develop the required information for the Technical Issues Management List data elements described above.

d. Maintain the schedule for issue resolution, and keep the decision-maker and champions informed.

e. Request needed resources and funding to resolve the issue.

f. Support preparation and staffing of any baseline change requests.

g. Make periodic status reports to the champions and decision-maker as required.

\subsubsection{Champions}

Duties may include:

a. Obtain resources as necessary including approval of change requests.

b. Coordinate personnel support as necessary.

c. . Sponsor the appropriate priority for the issue resolution activity.

d. Sponsor briefings to the Site Management Board and/or company senior management as necessary.

e. Take necessary follow-through action following decision-maker's action.

\subsubsection{Decision-Maker}

Duties may include:

a. Approve/disapprove the recommended issue resolution in a timely manner.

b. Provide direction for further action.

c. Disseminate decision information to actionees and interested parties.

d. Ensure actions are clearly assigned to responsible parties.

e. For Category 3 issues, ensure that the offsite decision-maker is informed of the Hanford planning assumption. 
PFP Issues/Assumptions Development

HNF-3725, Rev. 0

and Management Planning Guide

\subsection{Technical Issues Management List Maintenance}

\subsubsection{Closed Issues}

Closed issues will be maintained on the Technical Issues Management List for six months.

\subsubsection{Technical Issues Management List Publication}

The Technical Issues Management List is to be published monthly when changes have been made. If there are no changes, a letter is to be distributed stating the previous month's Technical Issues Management List is still current.

\subsection{Issue Analysis}

While the depth and level of technical analysis required for resolution of an issue will vary, several key features are required to maintain defensibility and consistency of the issue resolution process. Minimum requirements for an analysis are:

a. A clear and comprehensive statement of the problem. This will define the problem boundaries and ensure that what is included in the problem, as well as what is not included in the problem, is defined.

b. A clear and comprehensive statement of the required decision which resolves the issue.

c. A set of alternative solutions, approaches or architectures which would resolve the issue.

NOTE: Where these alternatives have been identified and analyzed in the past, this step can be replaced with appropriate references to previous work.

d. A set of evaluation criteria which are used to analyze and compare the performance of the alternatives.

e. Identification of the selected alternative and a defense of the selection.

f. Concurrence of the affected organizations.

\subsection{Issue Prioritization}

Issue prioritization is a subjective categorization based on considerations of the Environmental, Safety and Health (ES\&H) impact, financial impact, and timing of the need for resolution of the issue. 
This page intentionally left blank. 
PFP Issues/Assumptions Development

HNF-3725, Rev. 0 and Management Planning Guide

\section{Appendix A}

Open Issues and Assumptions Management List 


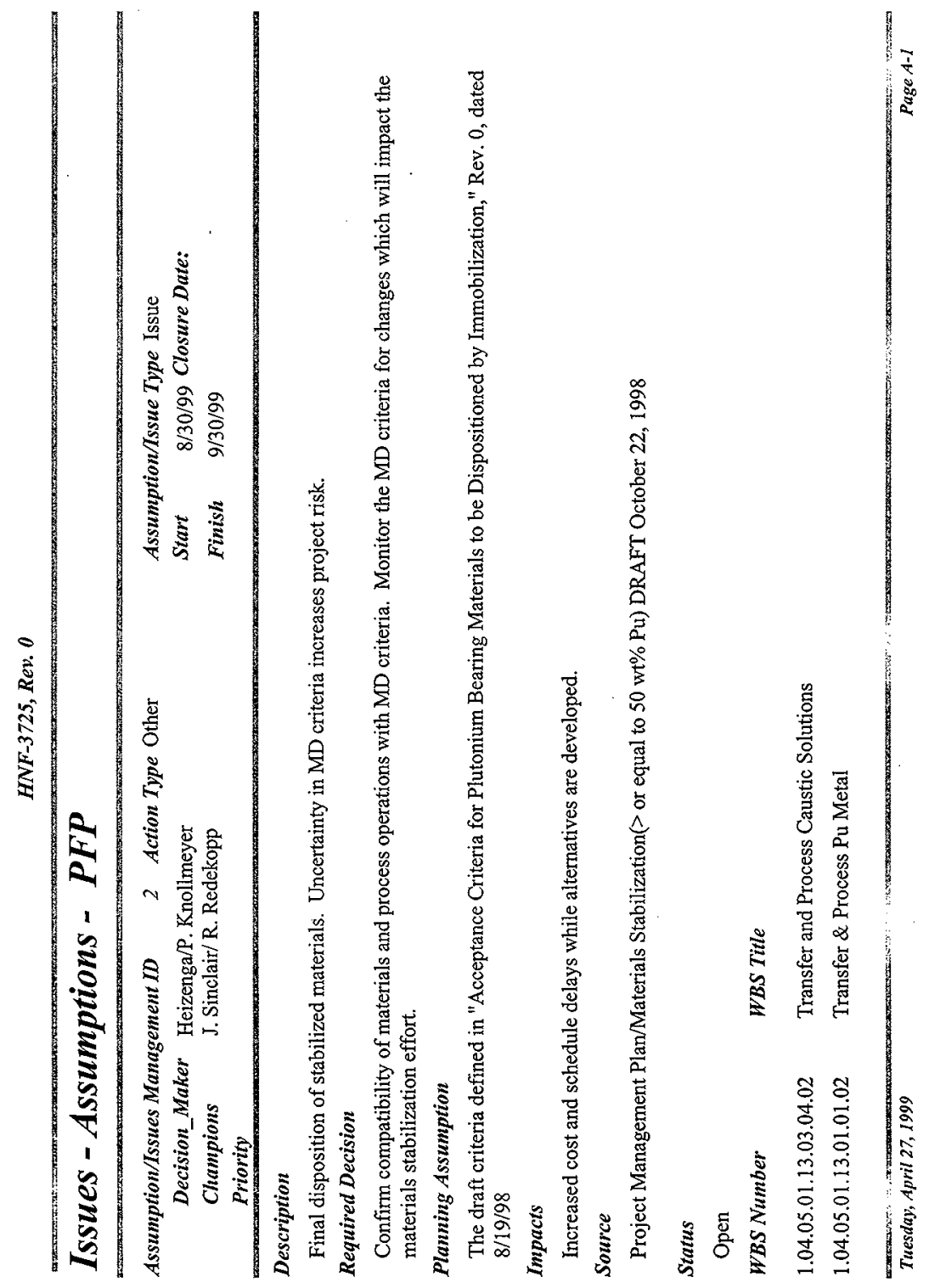



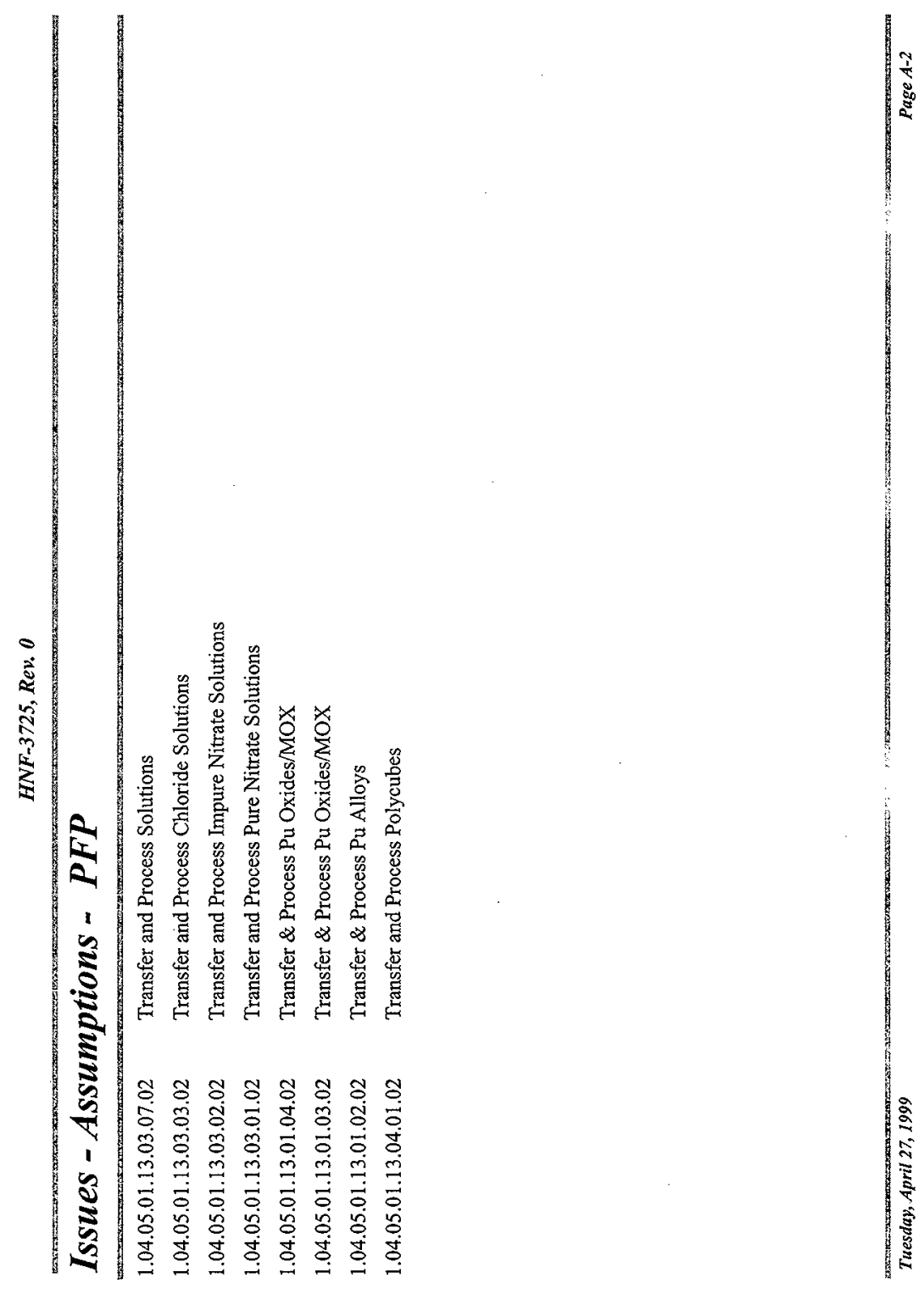


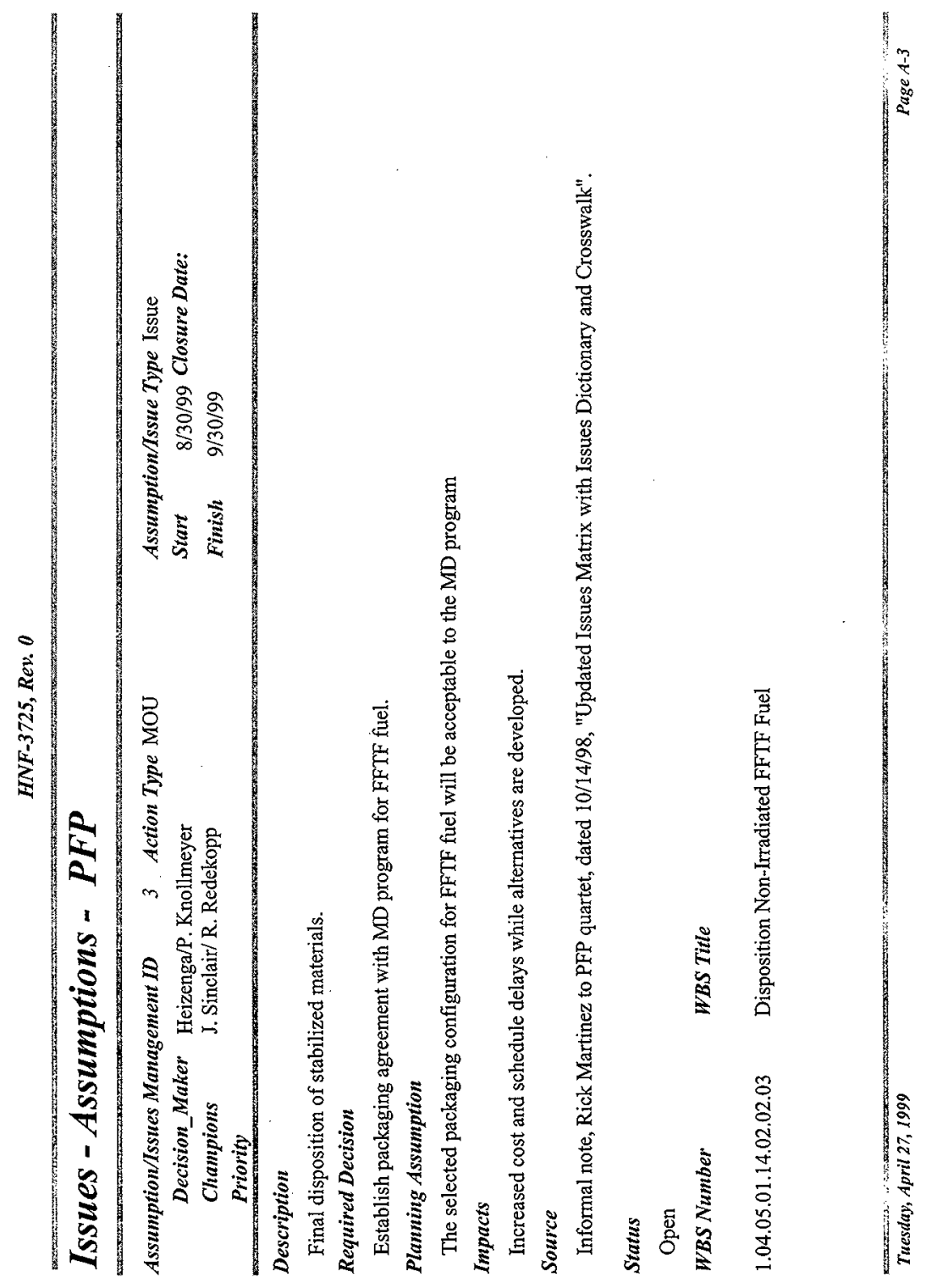




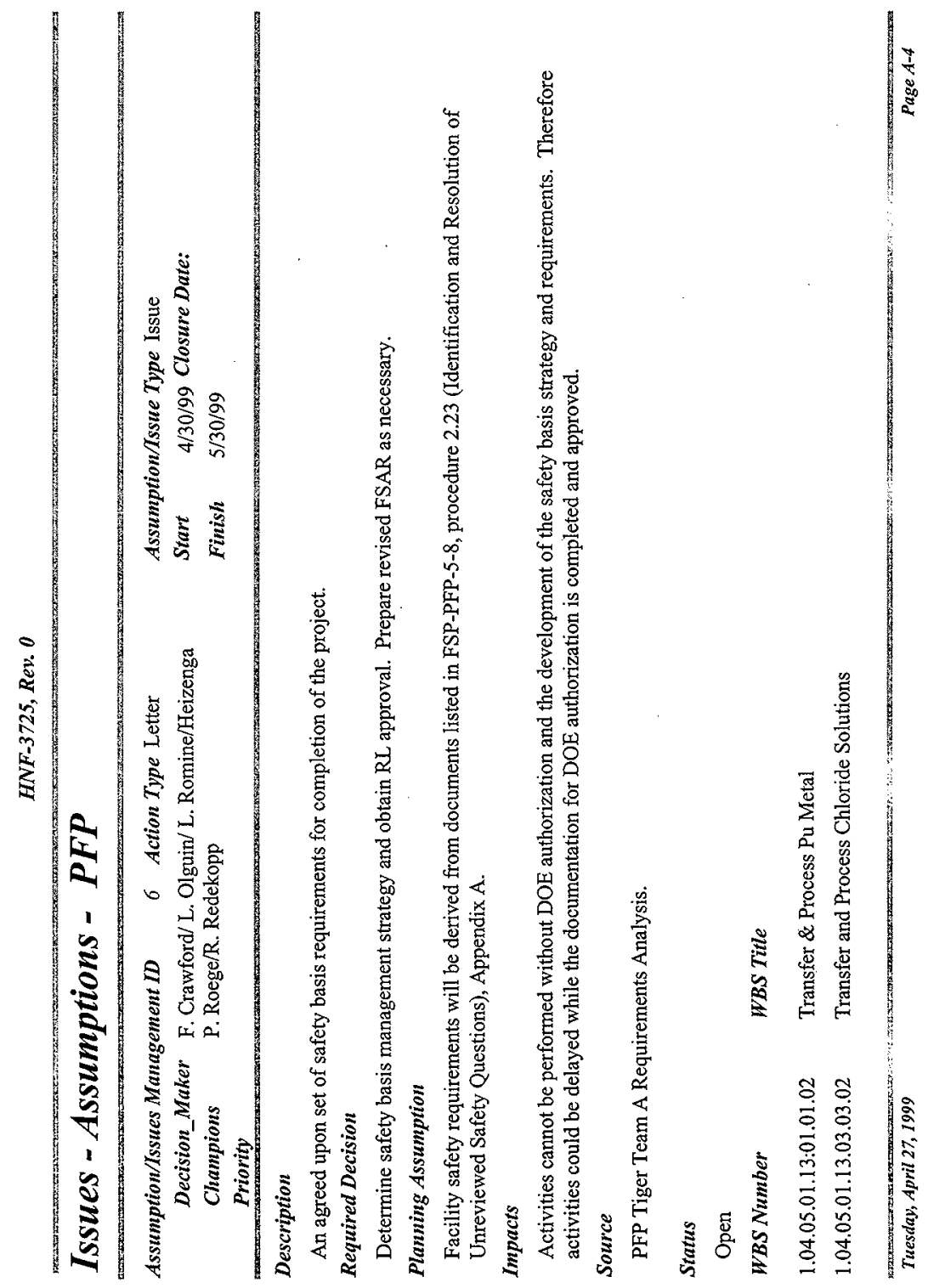




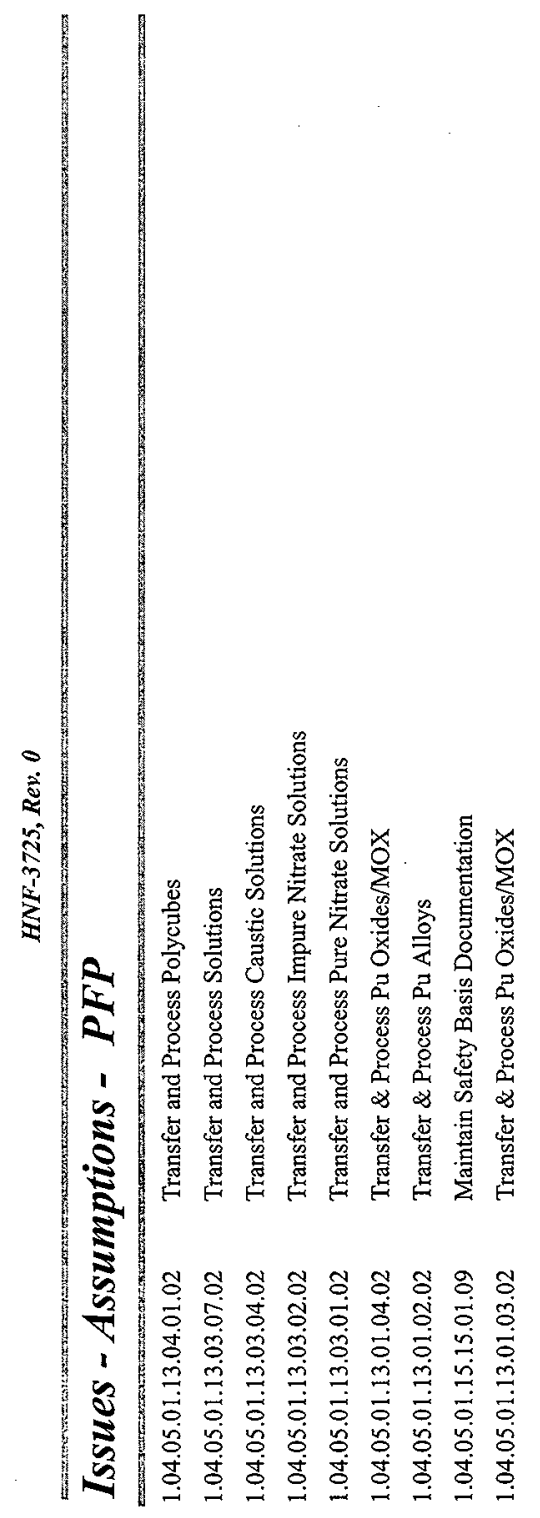




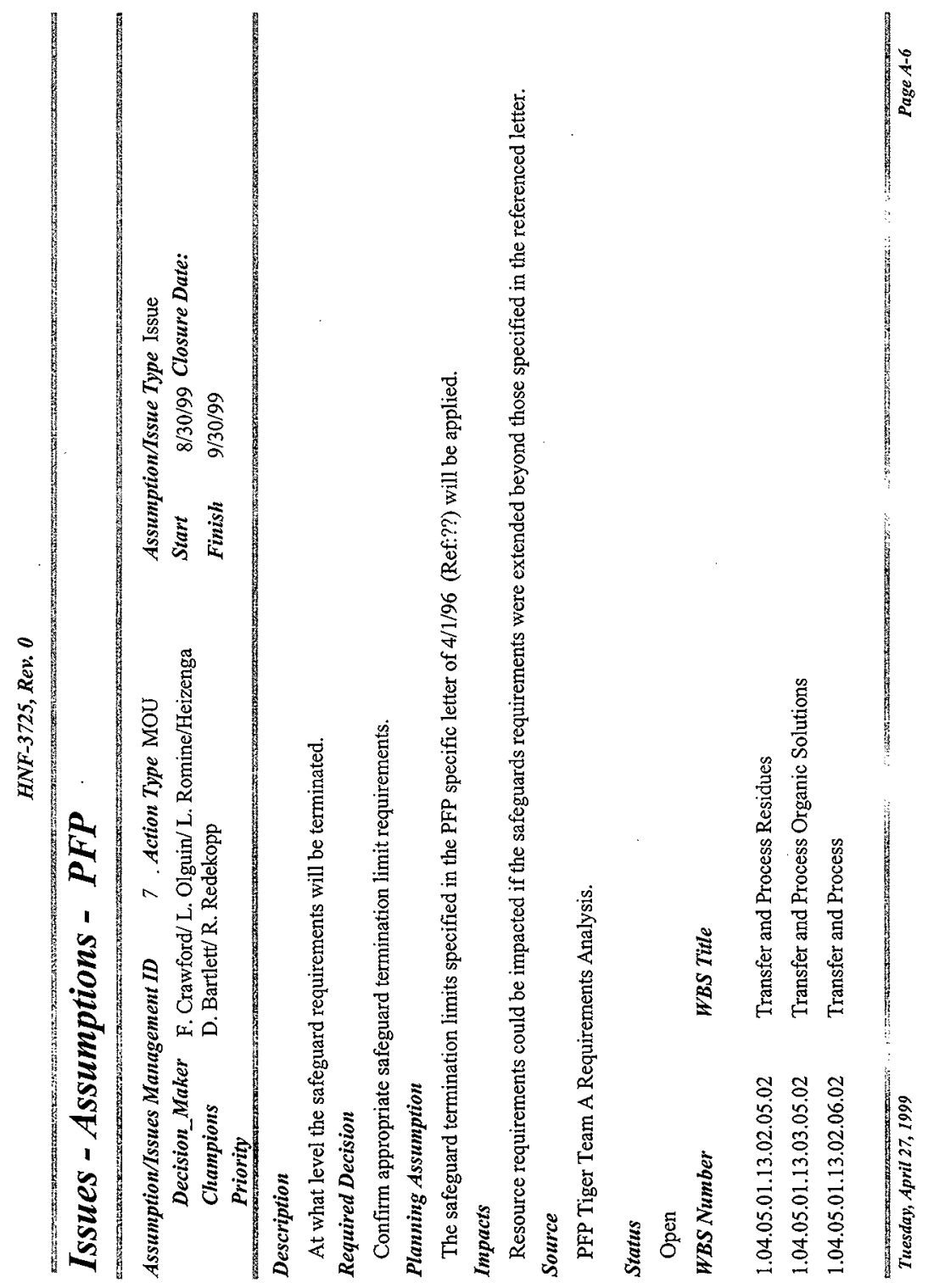



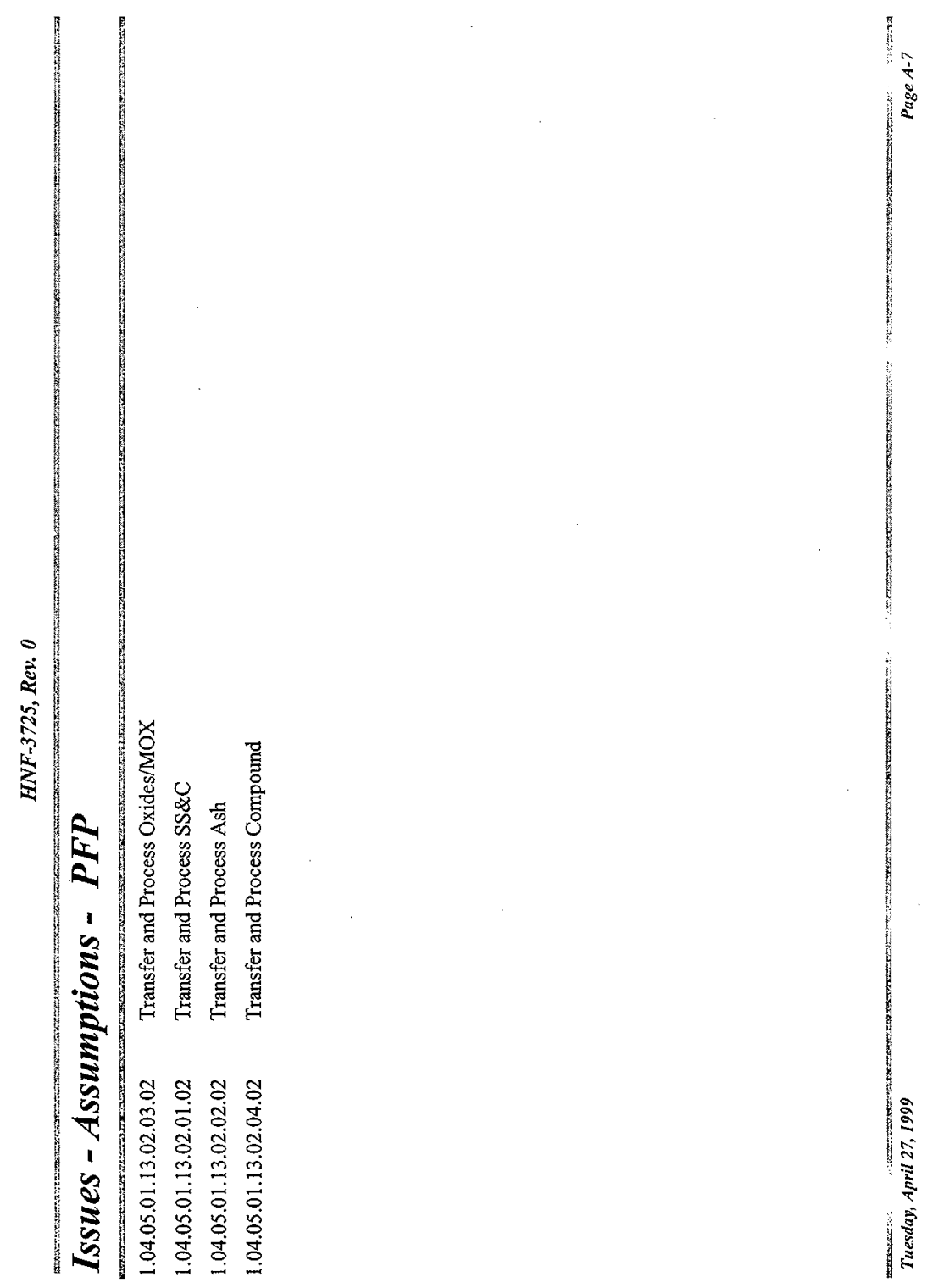


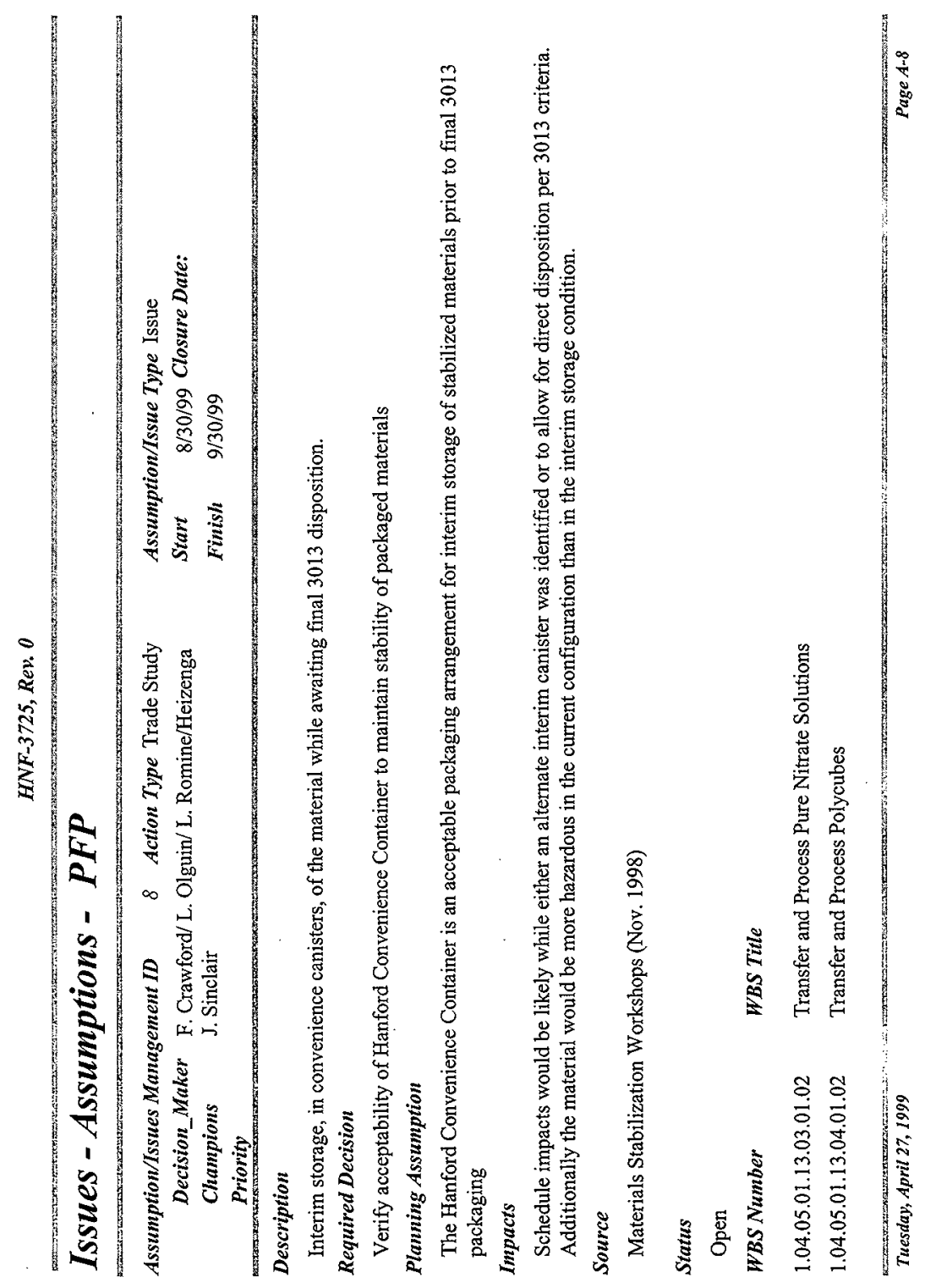




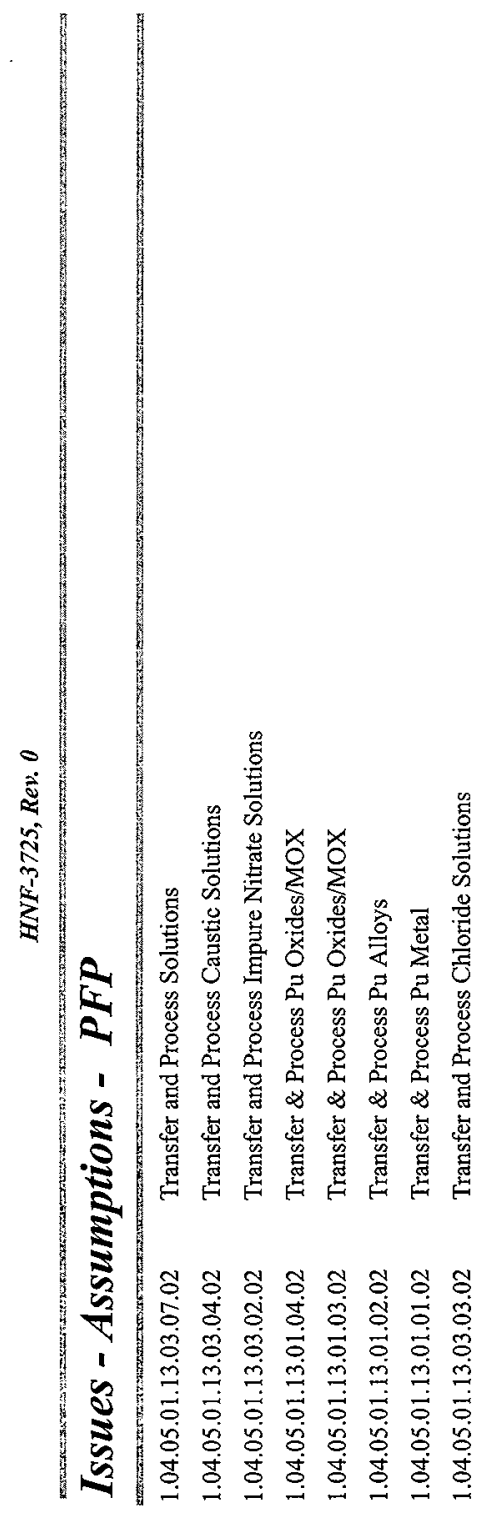




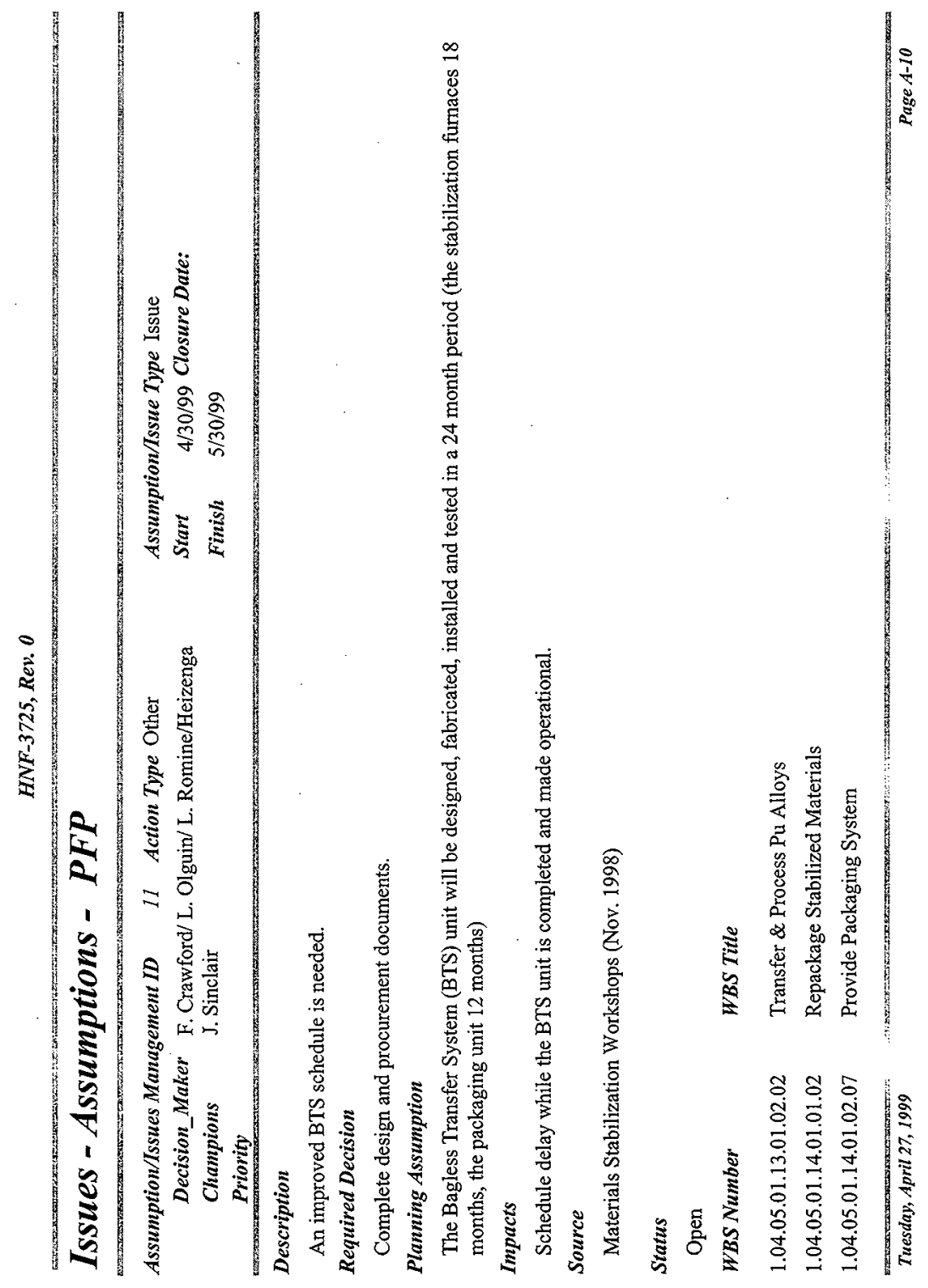




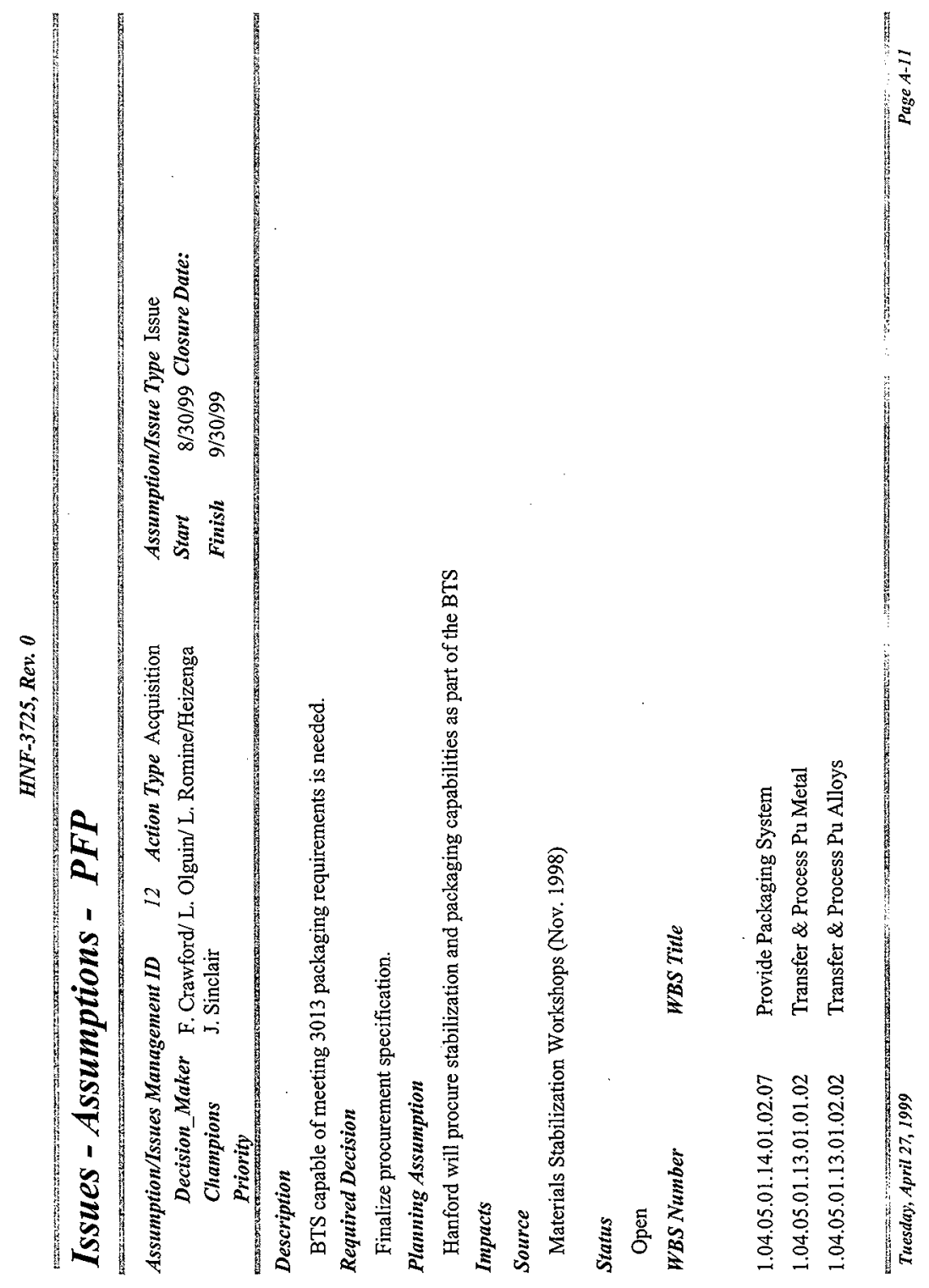




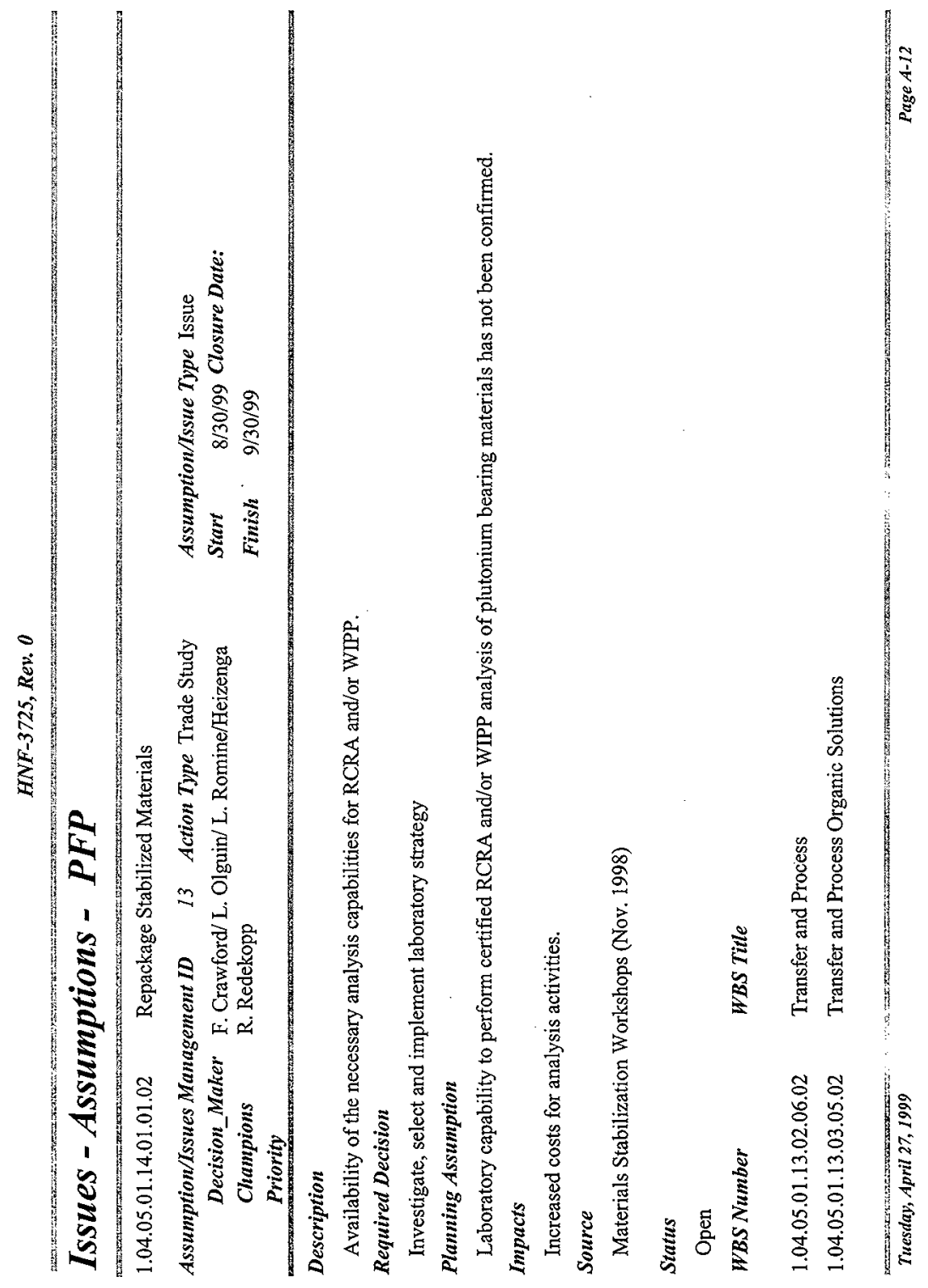




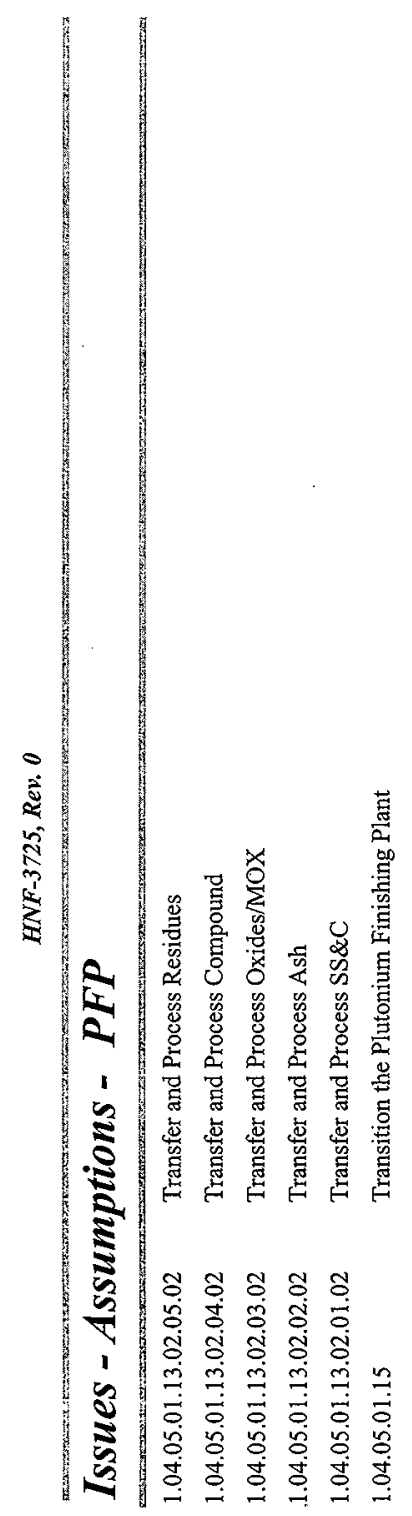



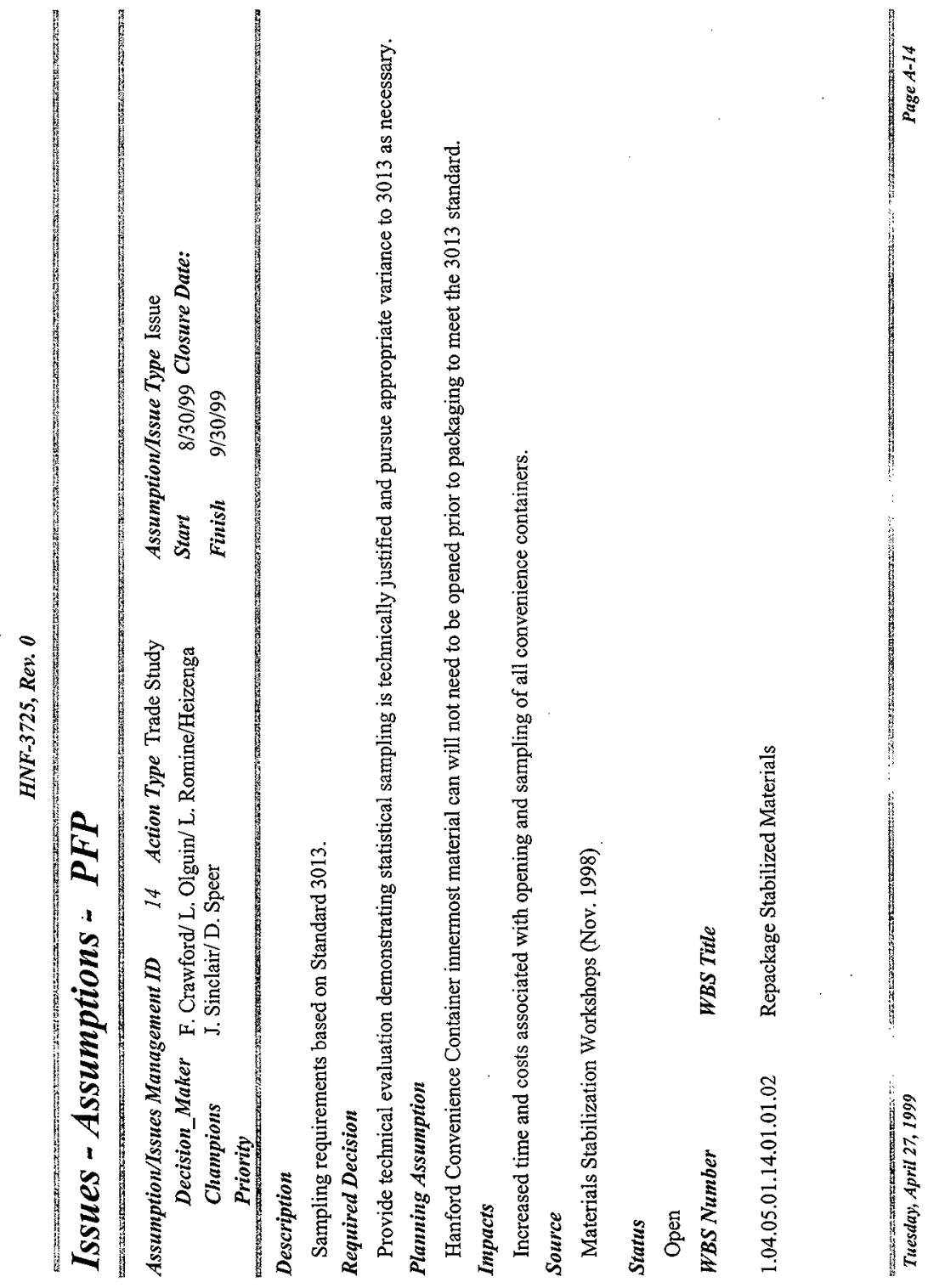


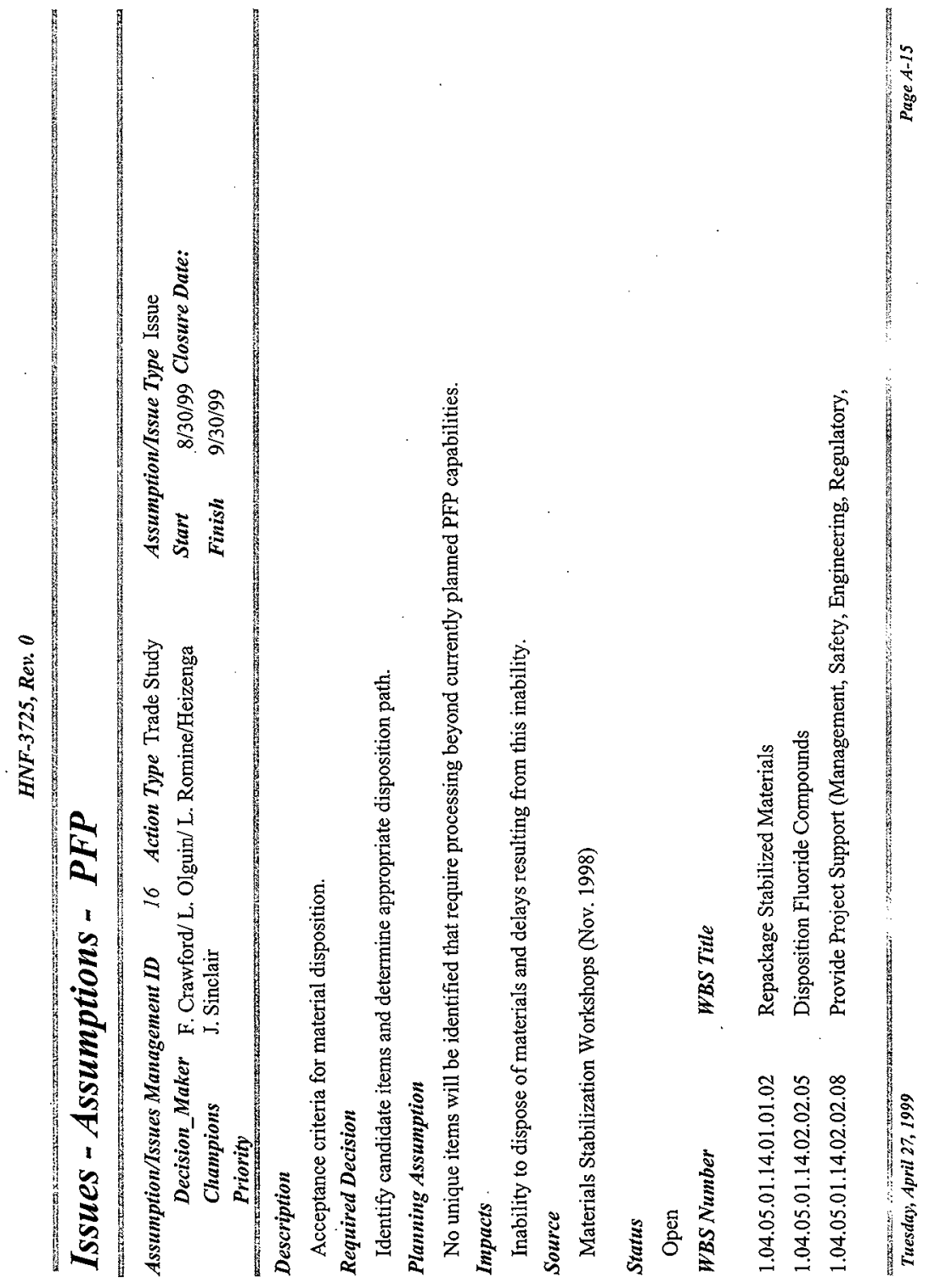



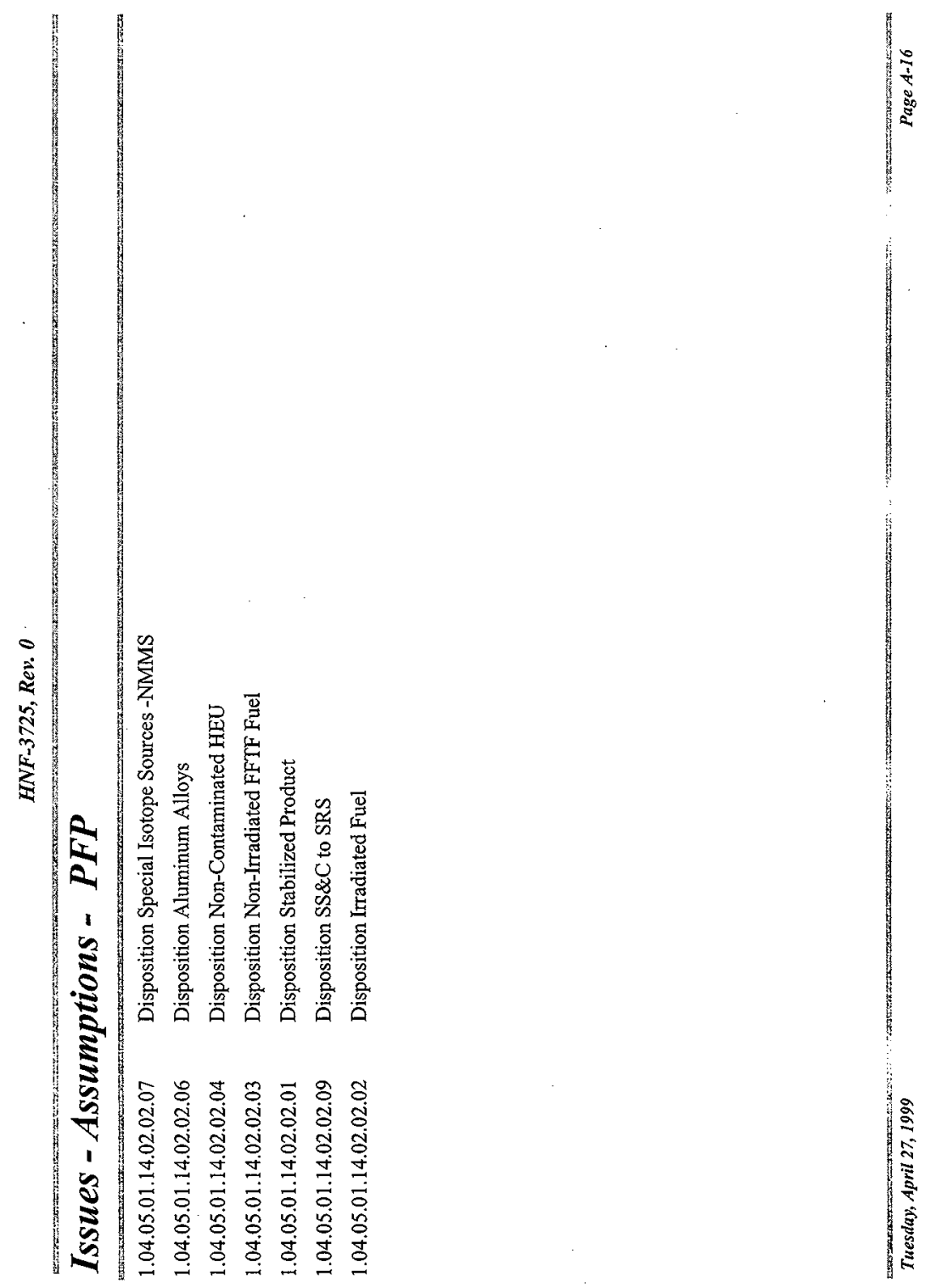


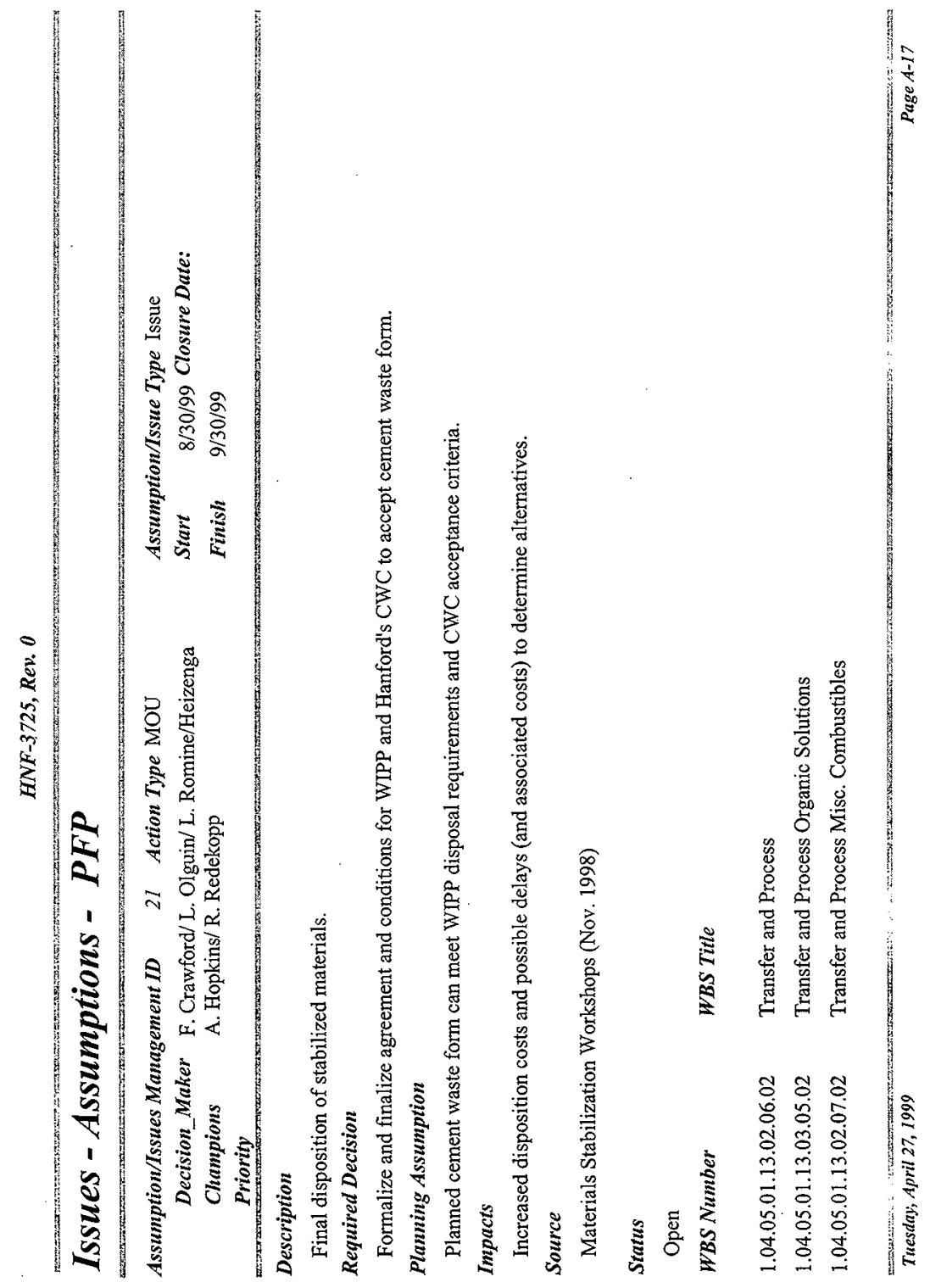




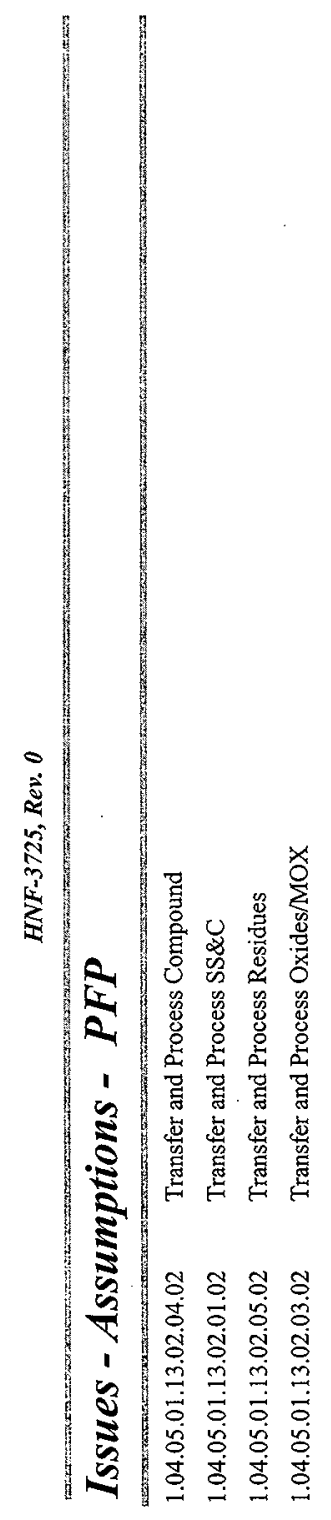




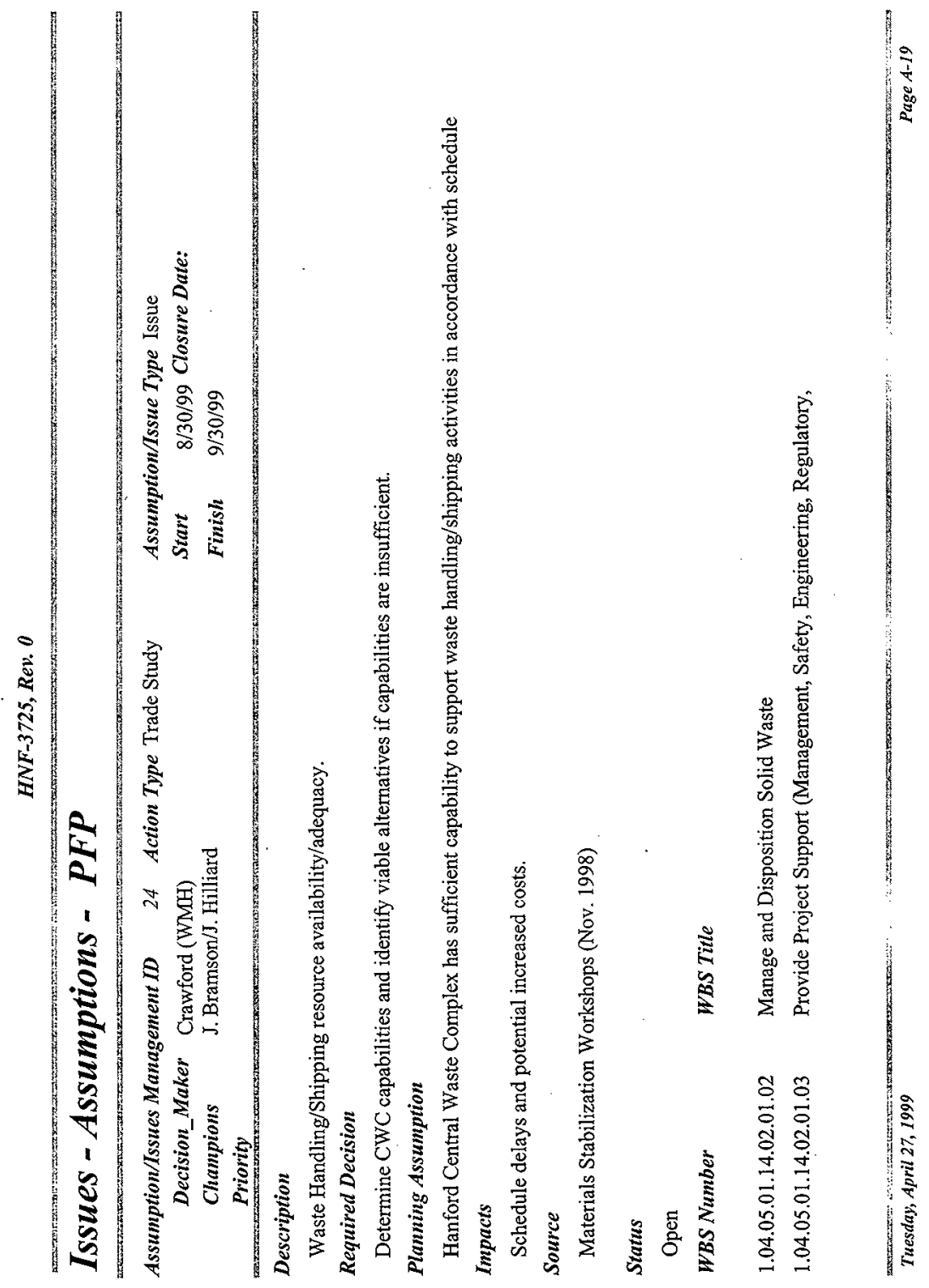




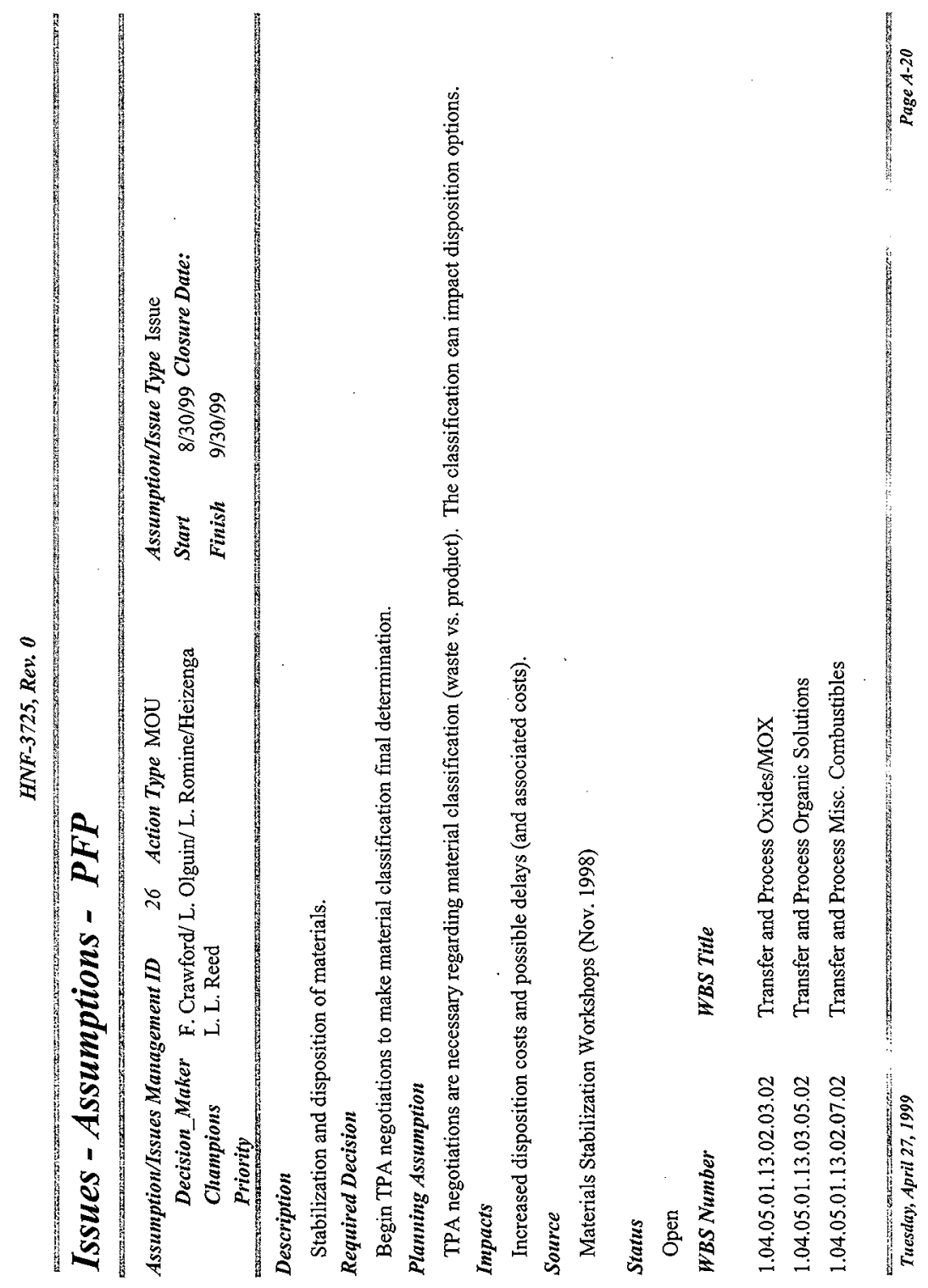




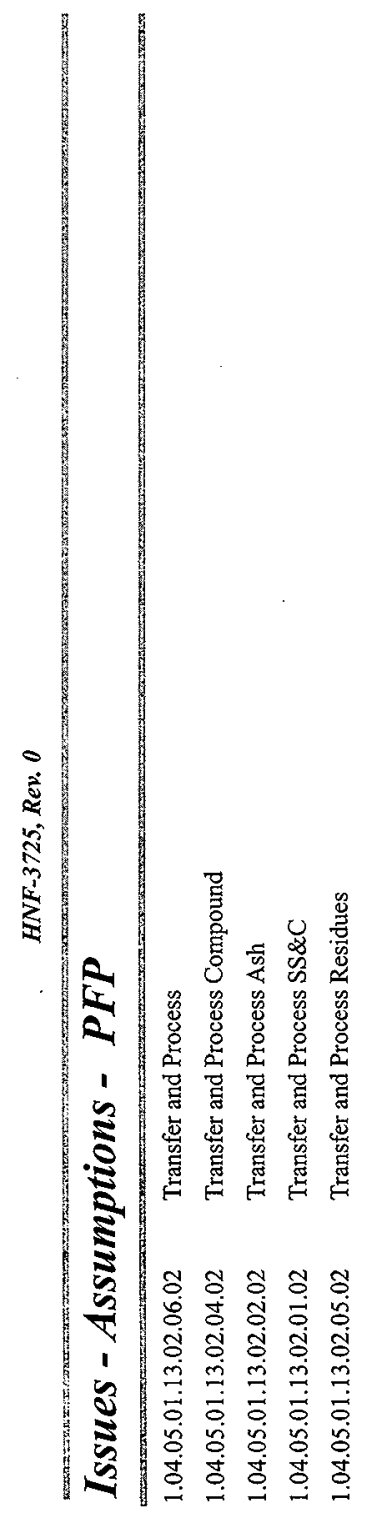




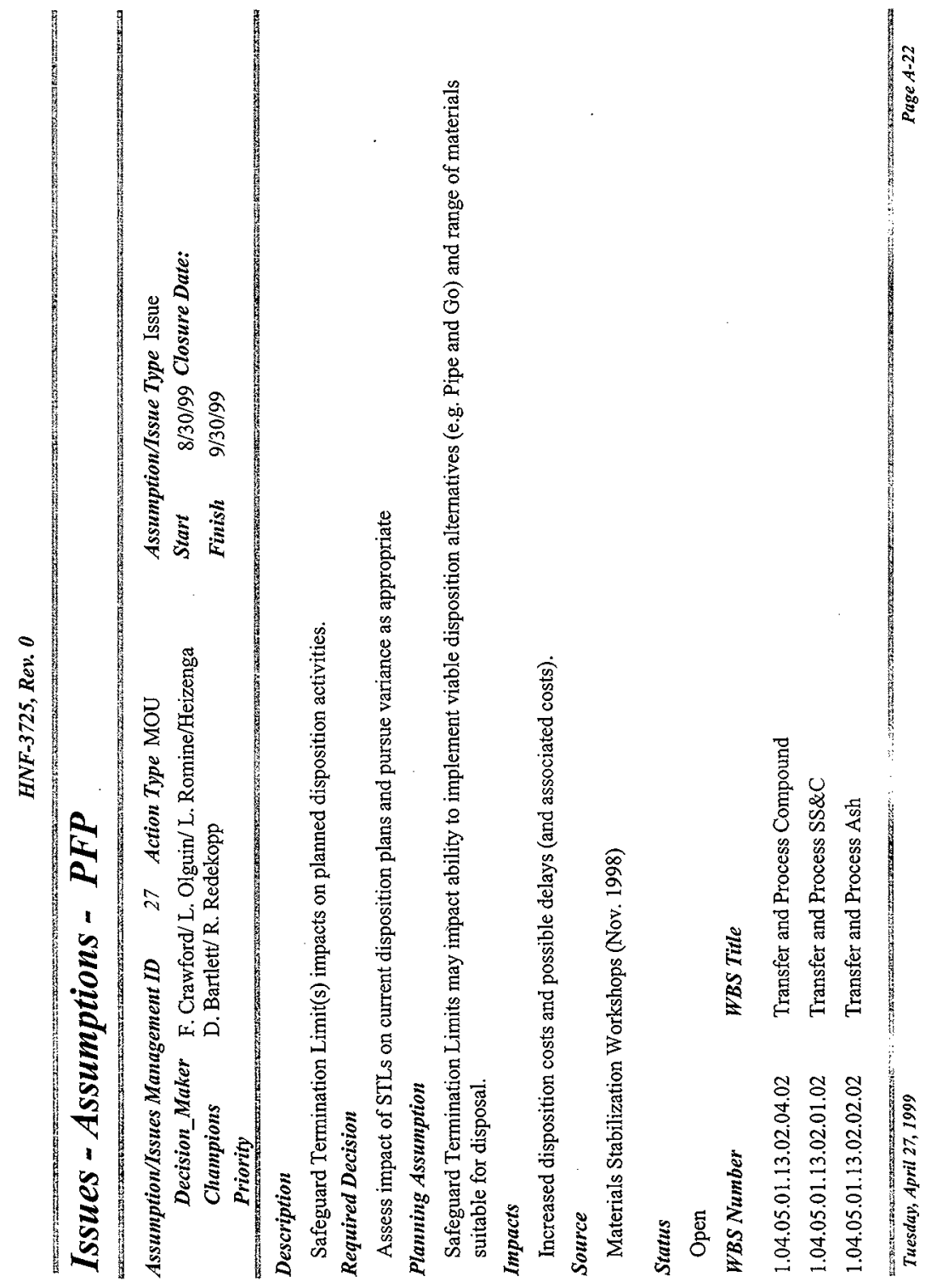



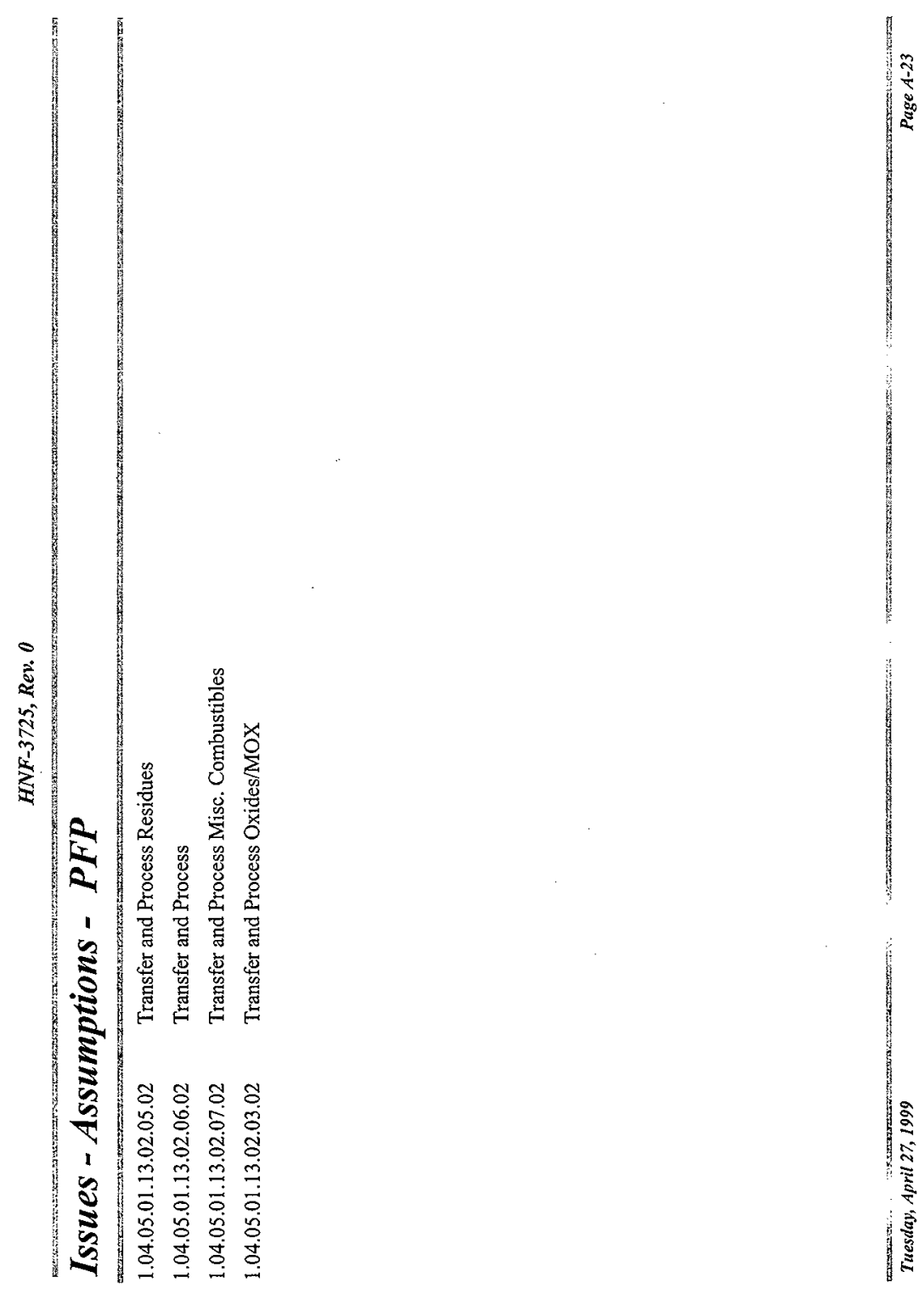


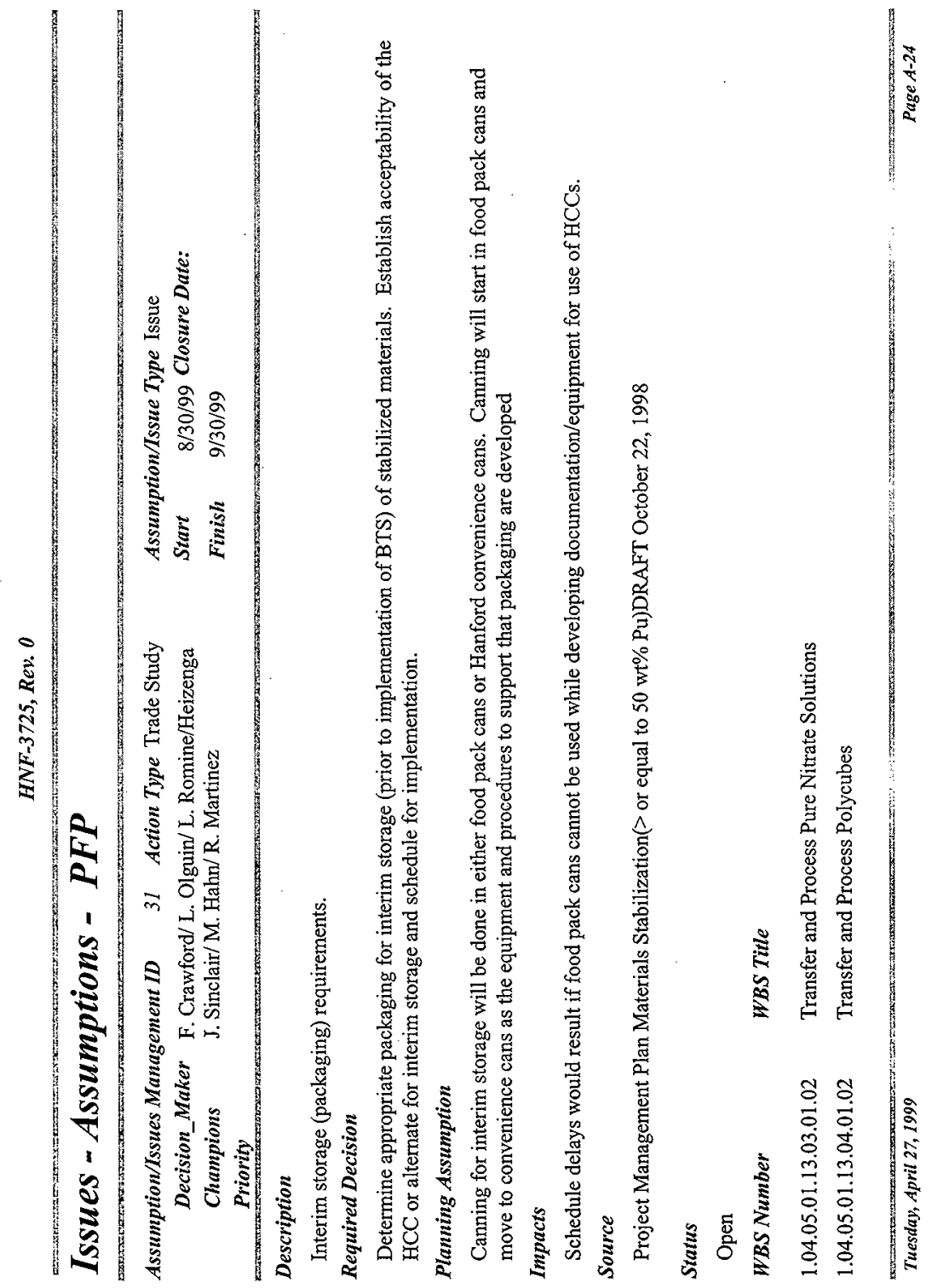




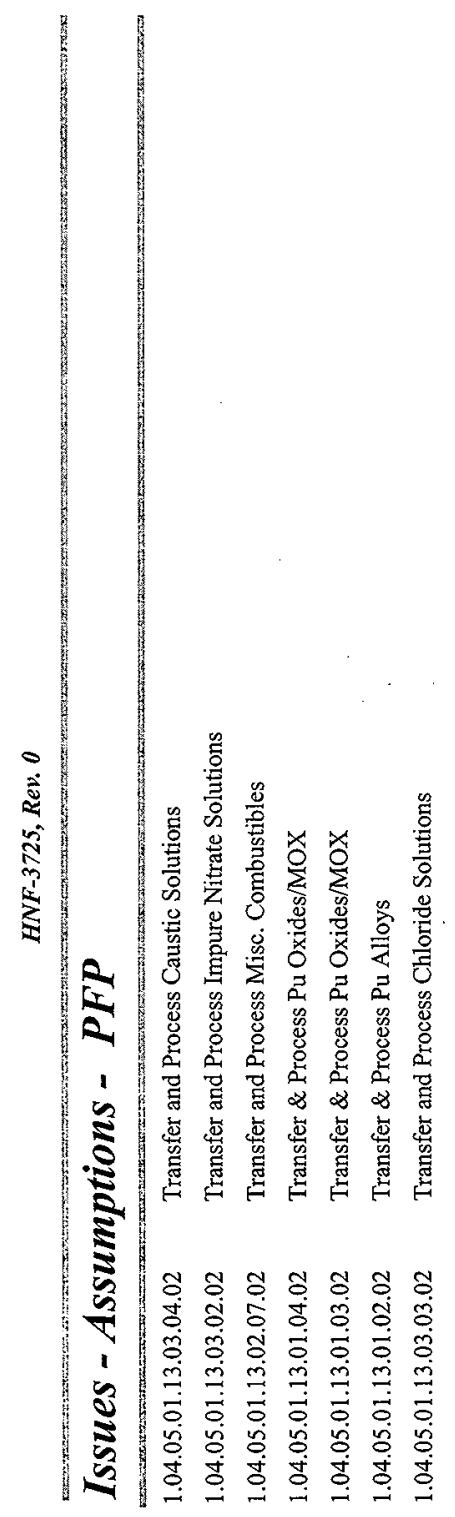




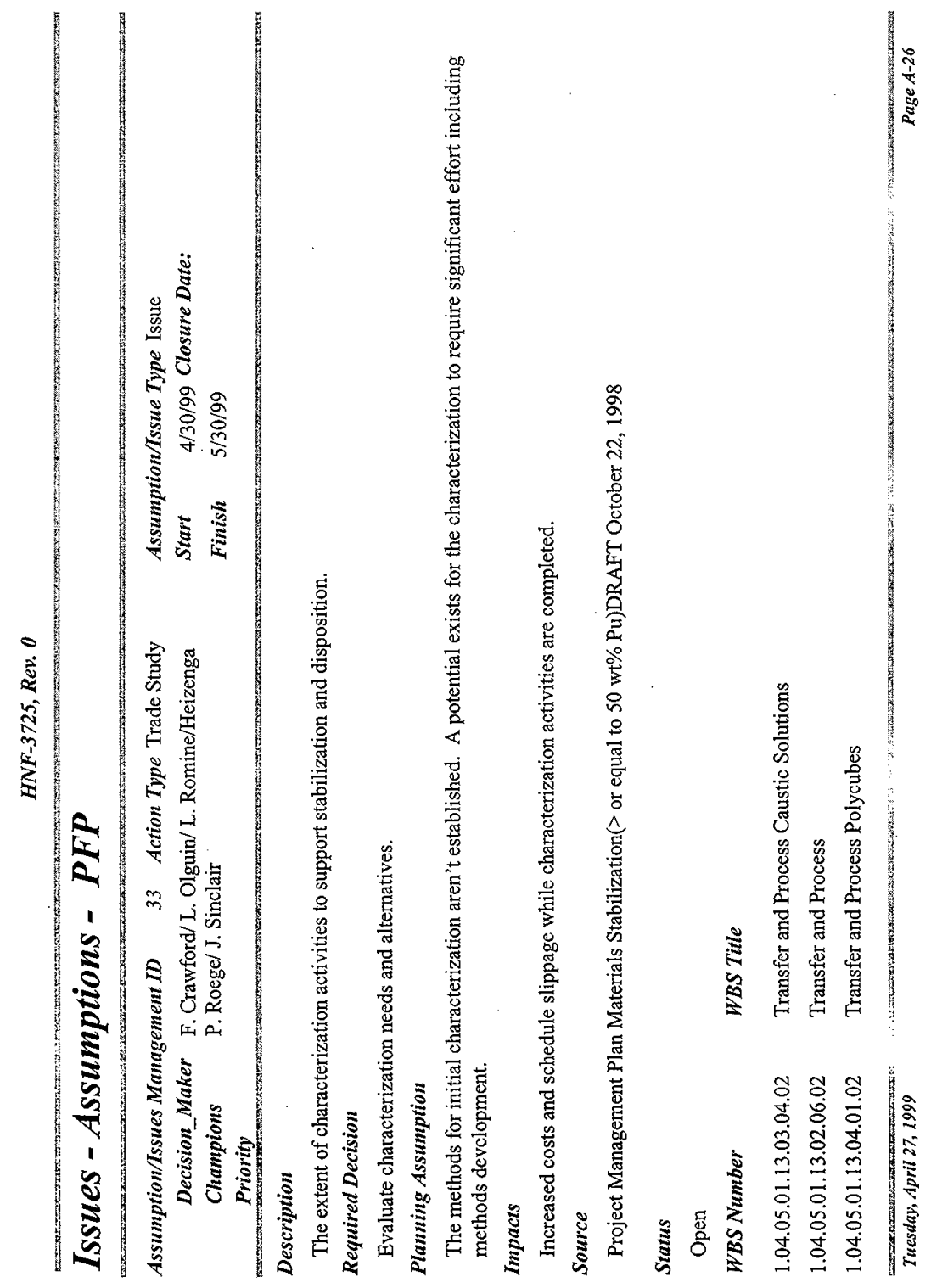



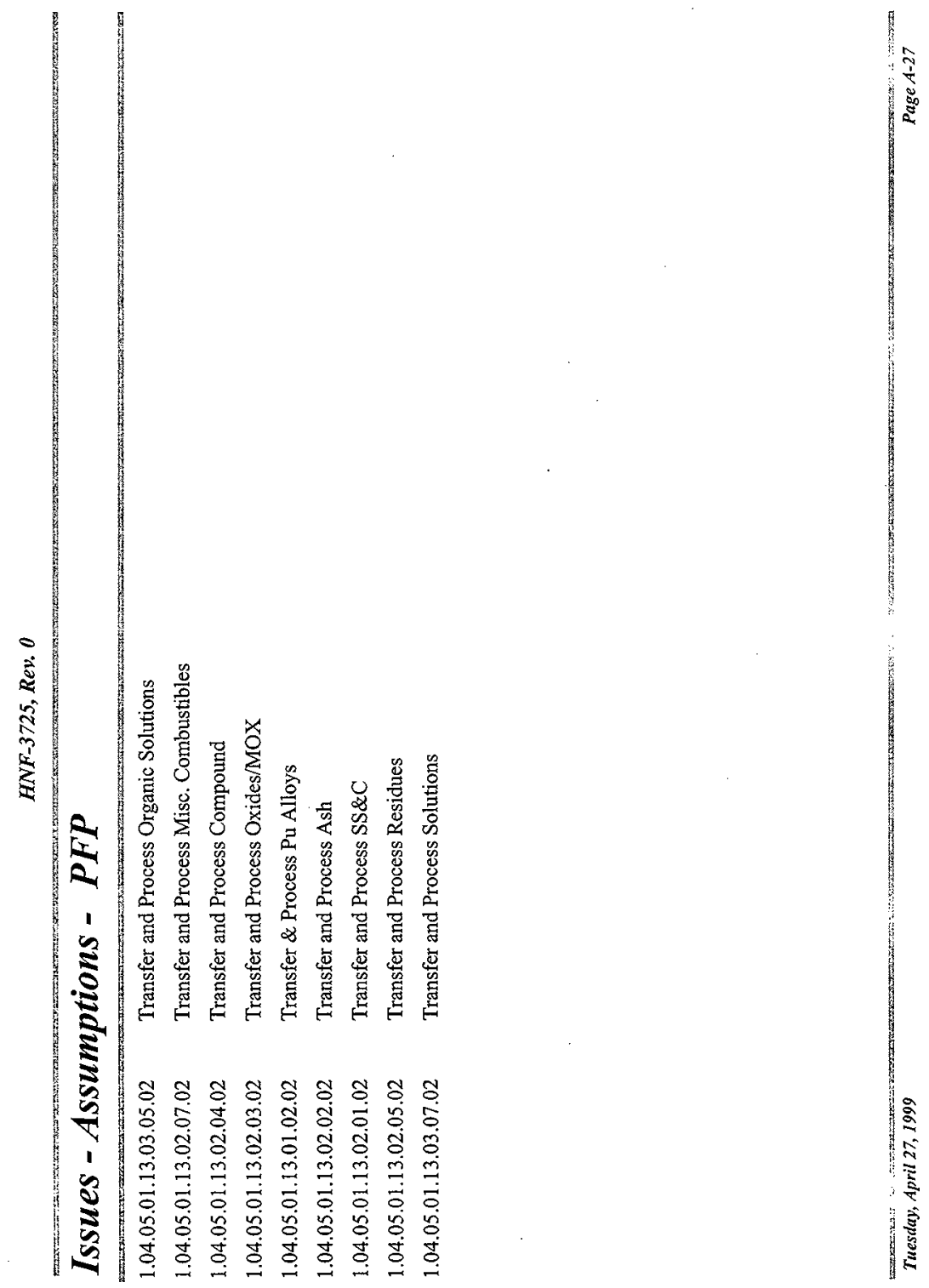


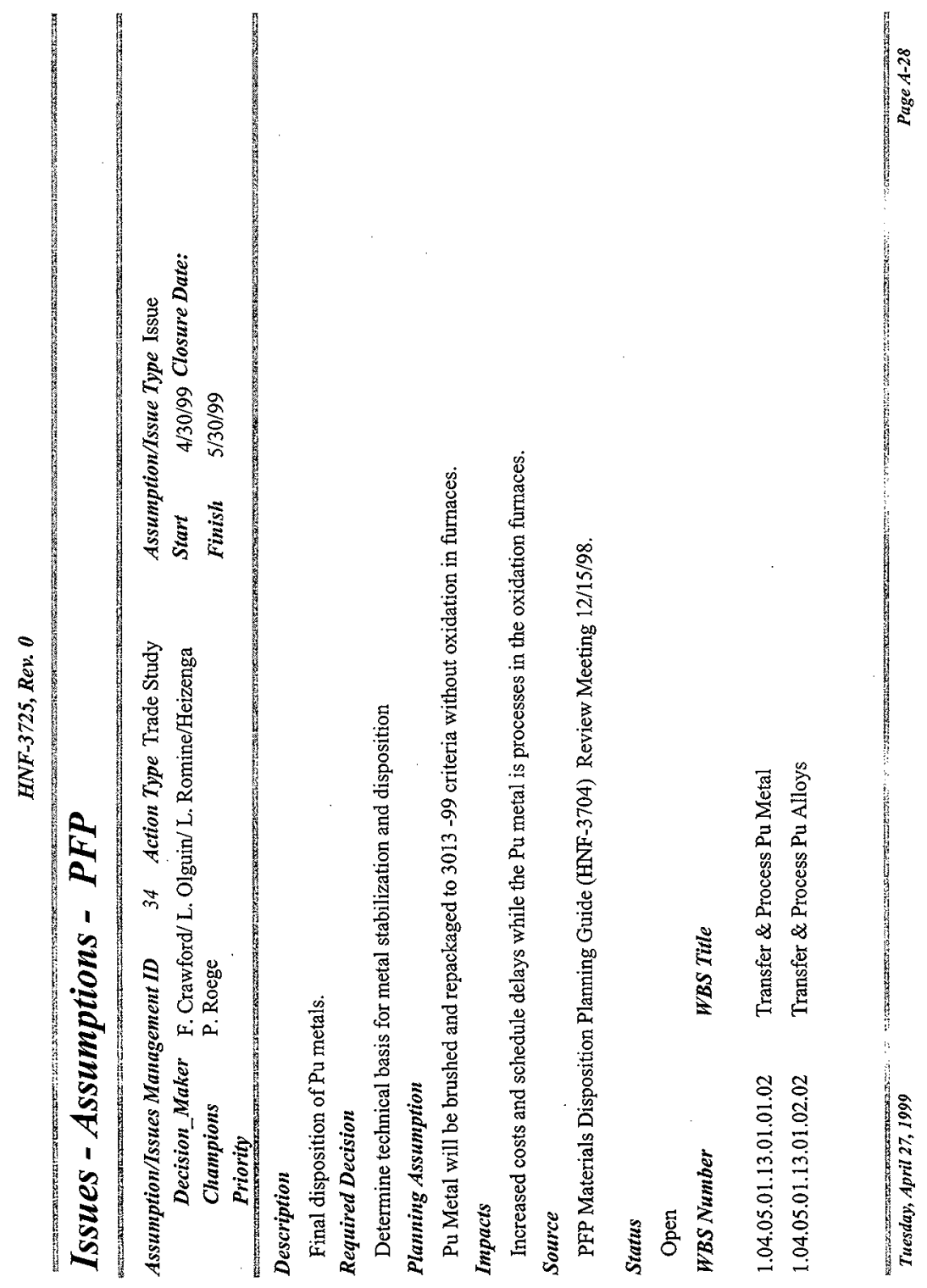



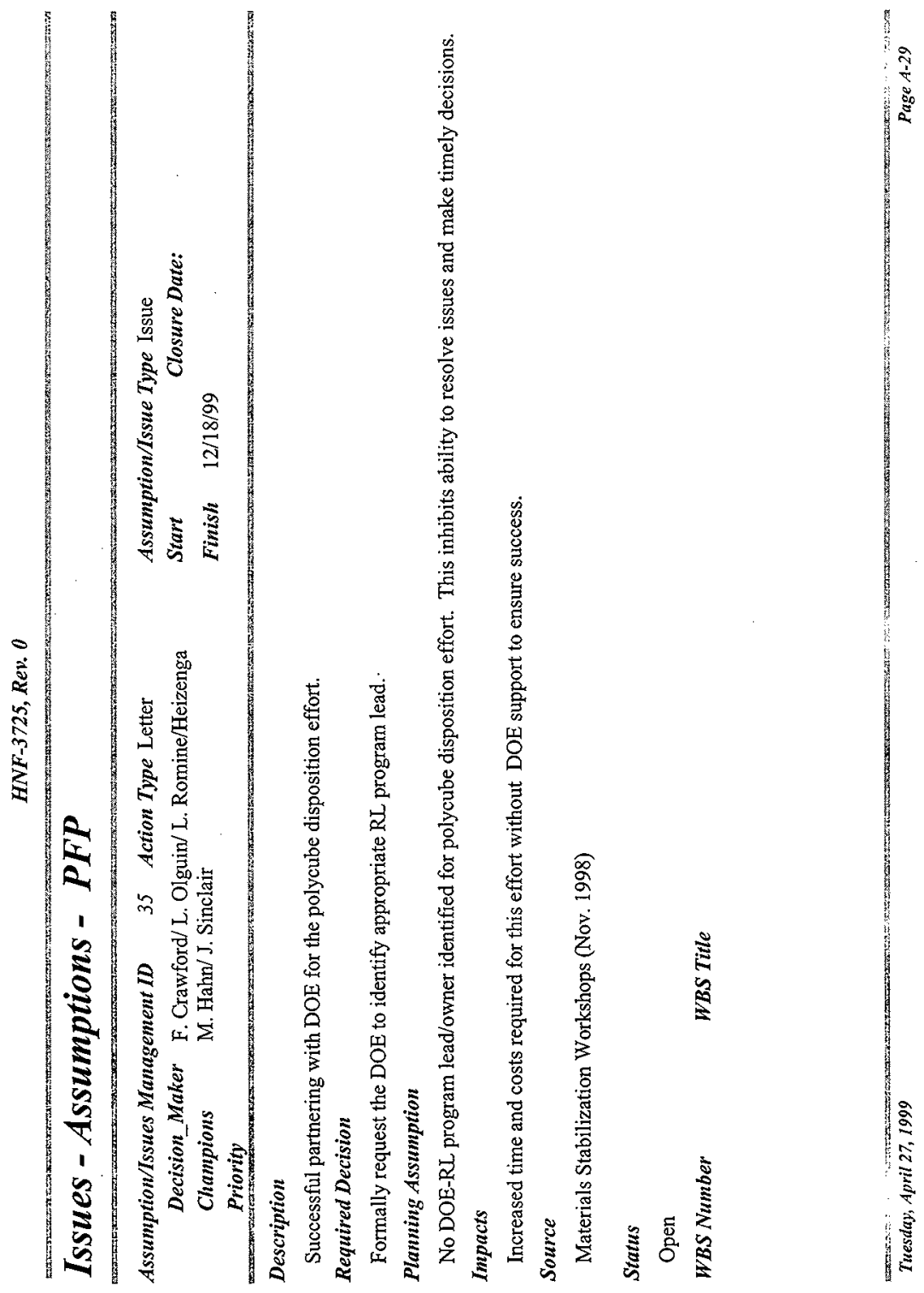

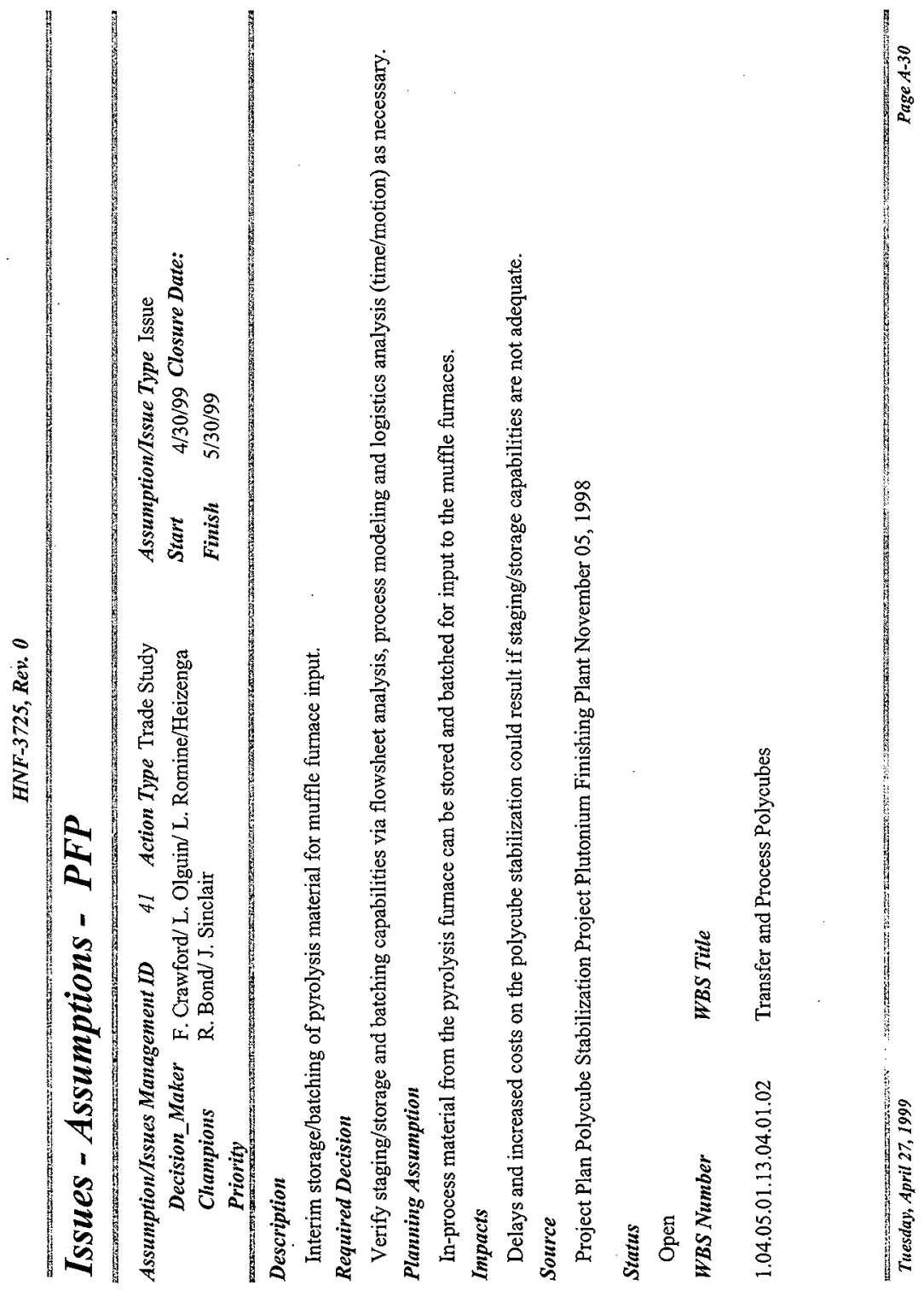

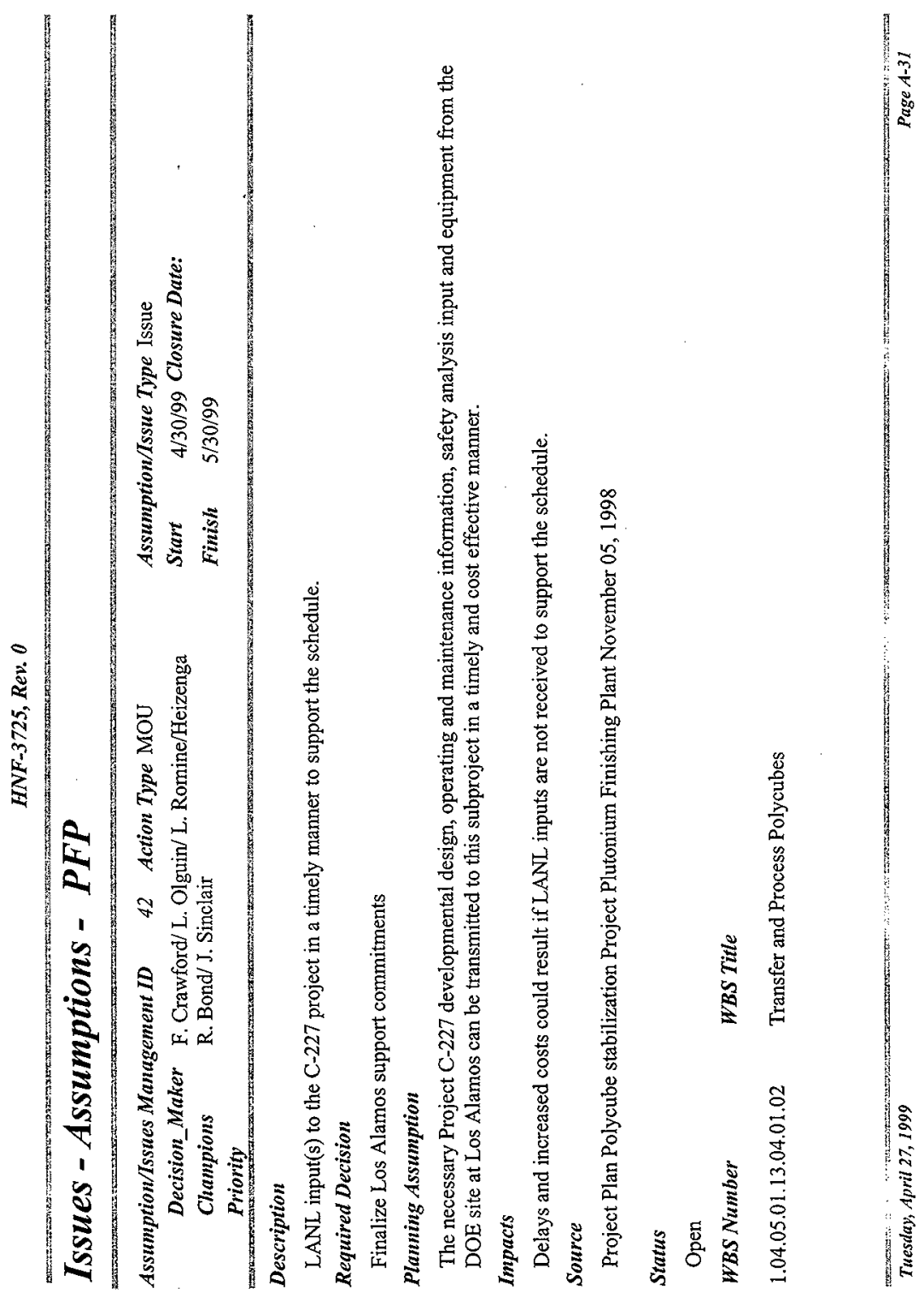


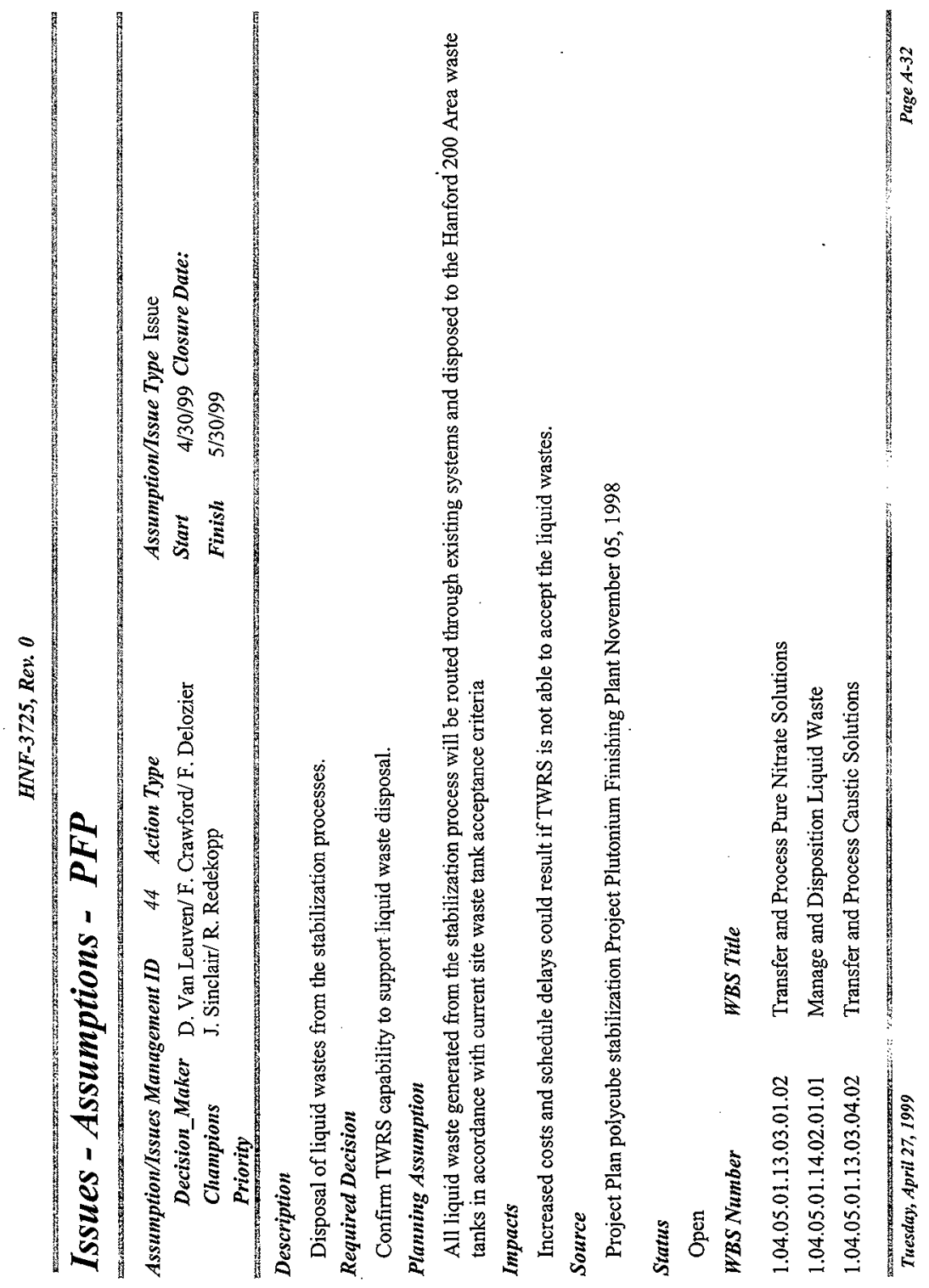




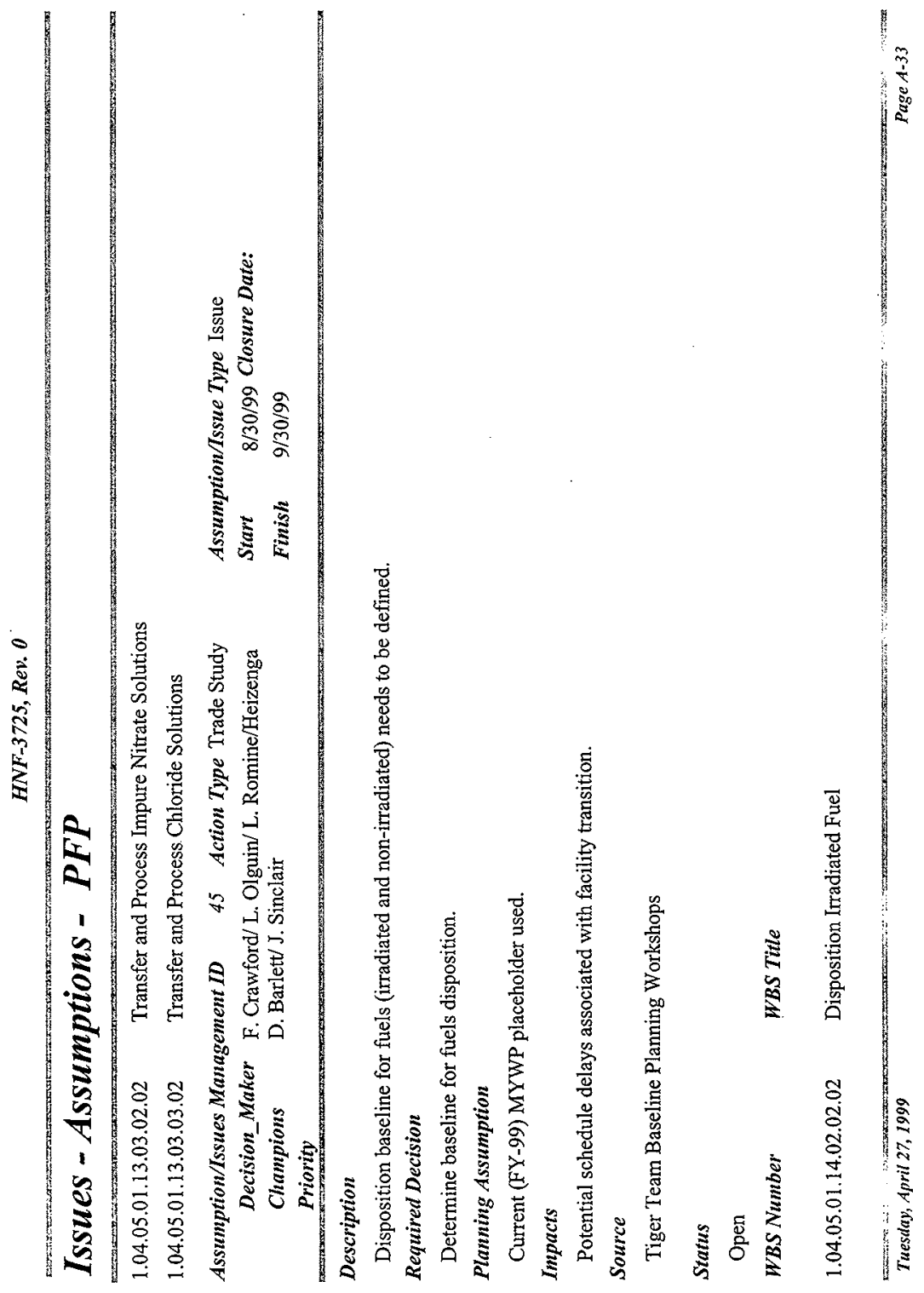




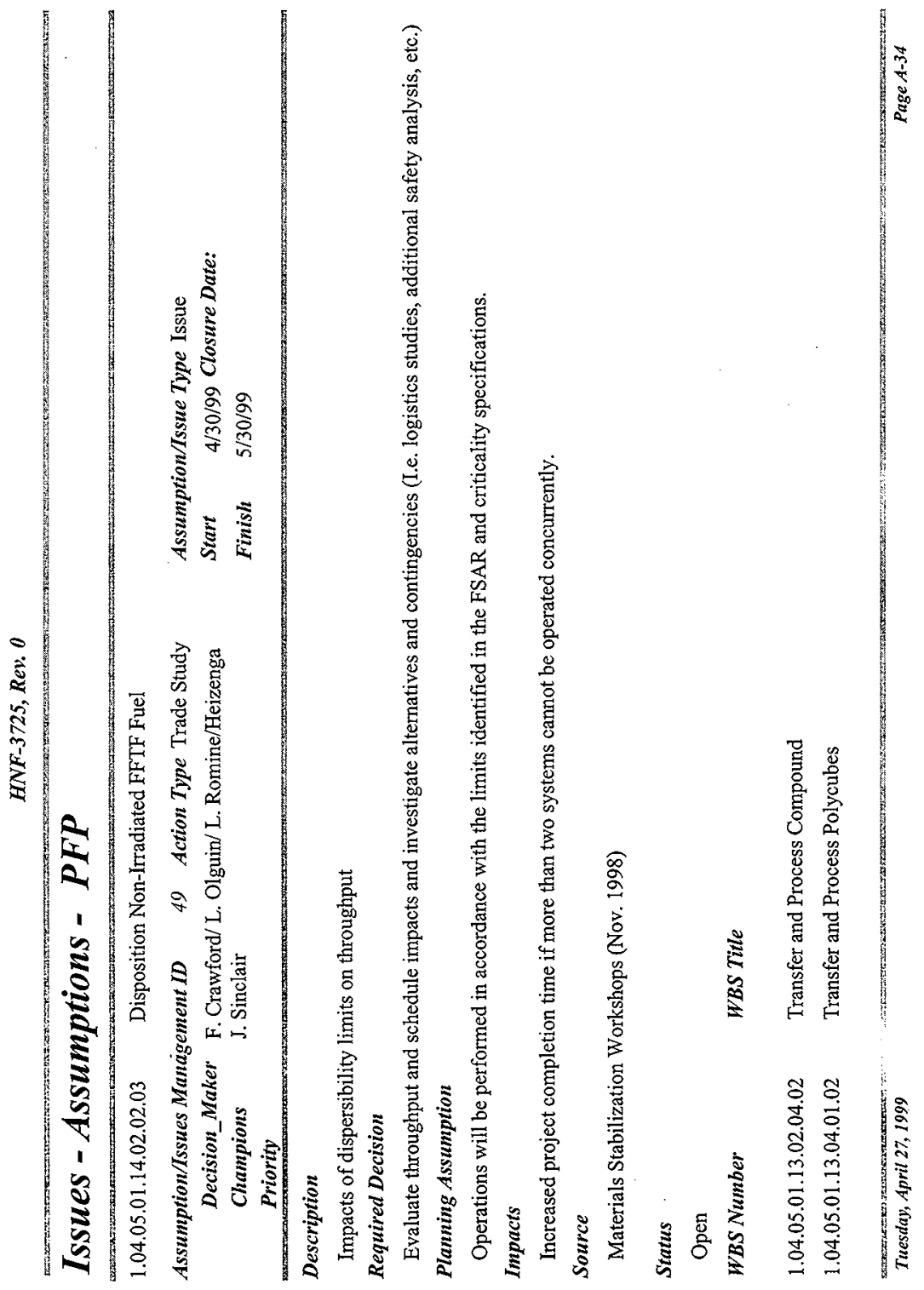




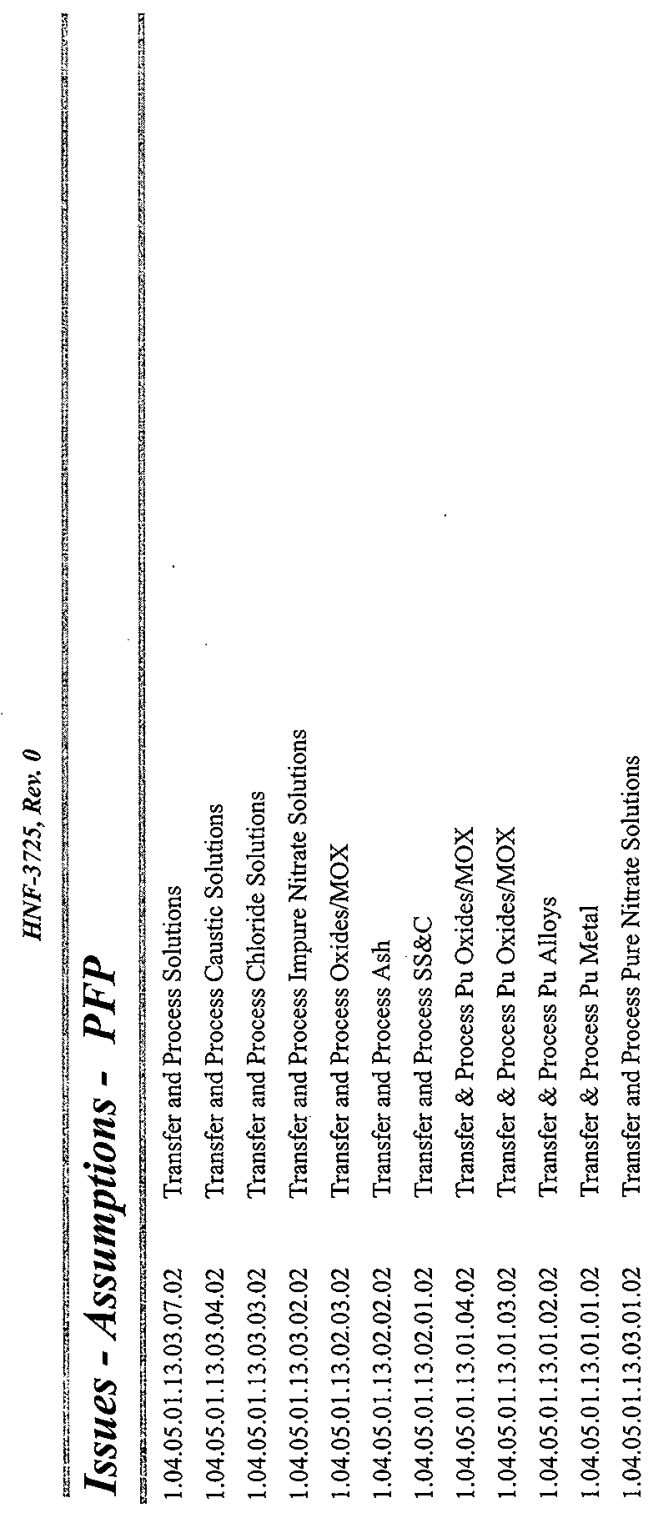




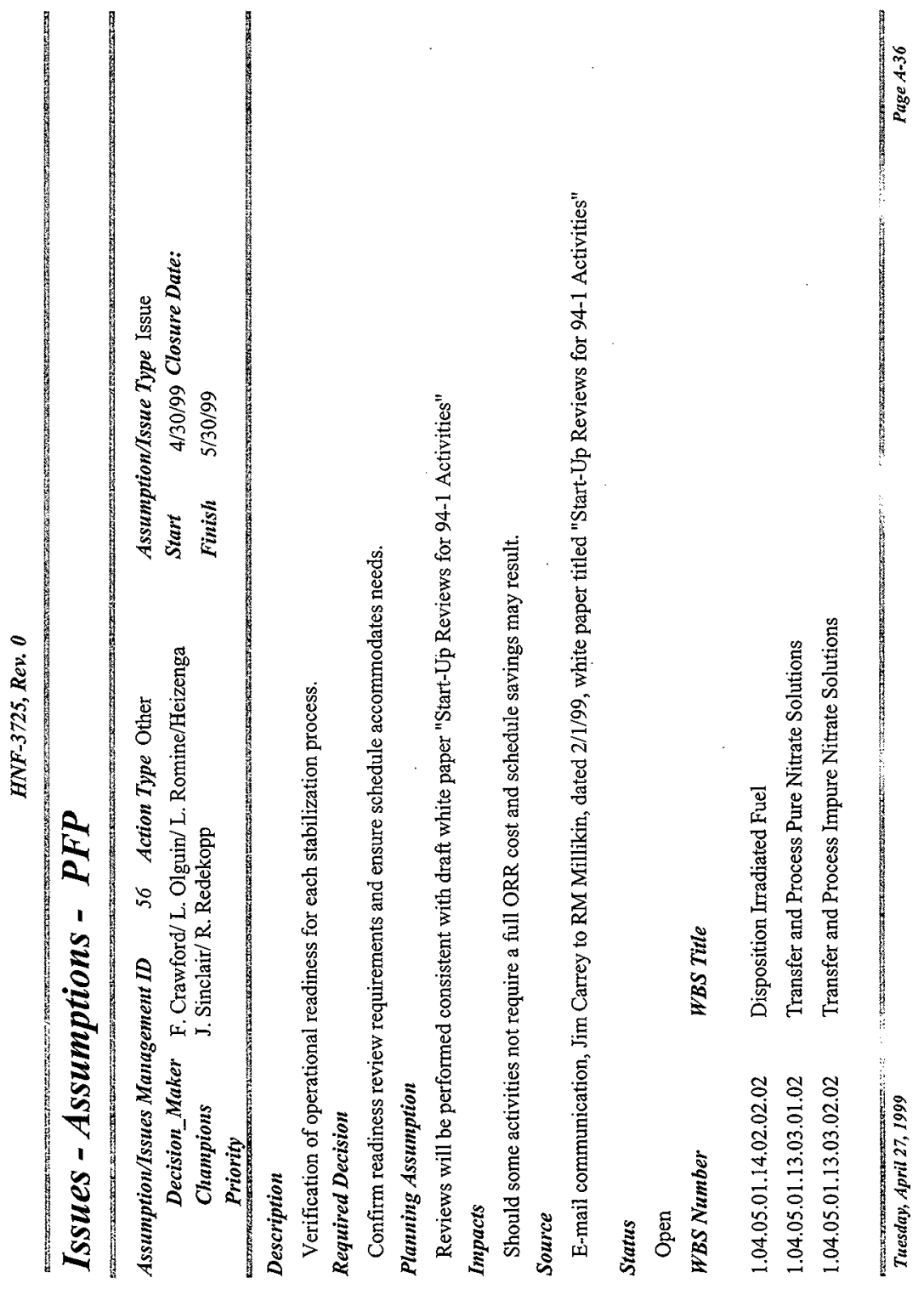




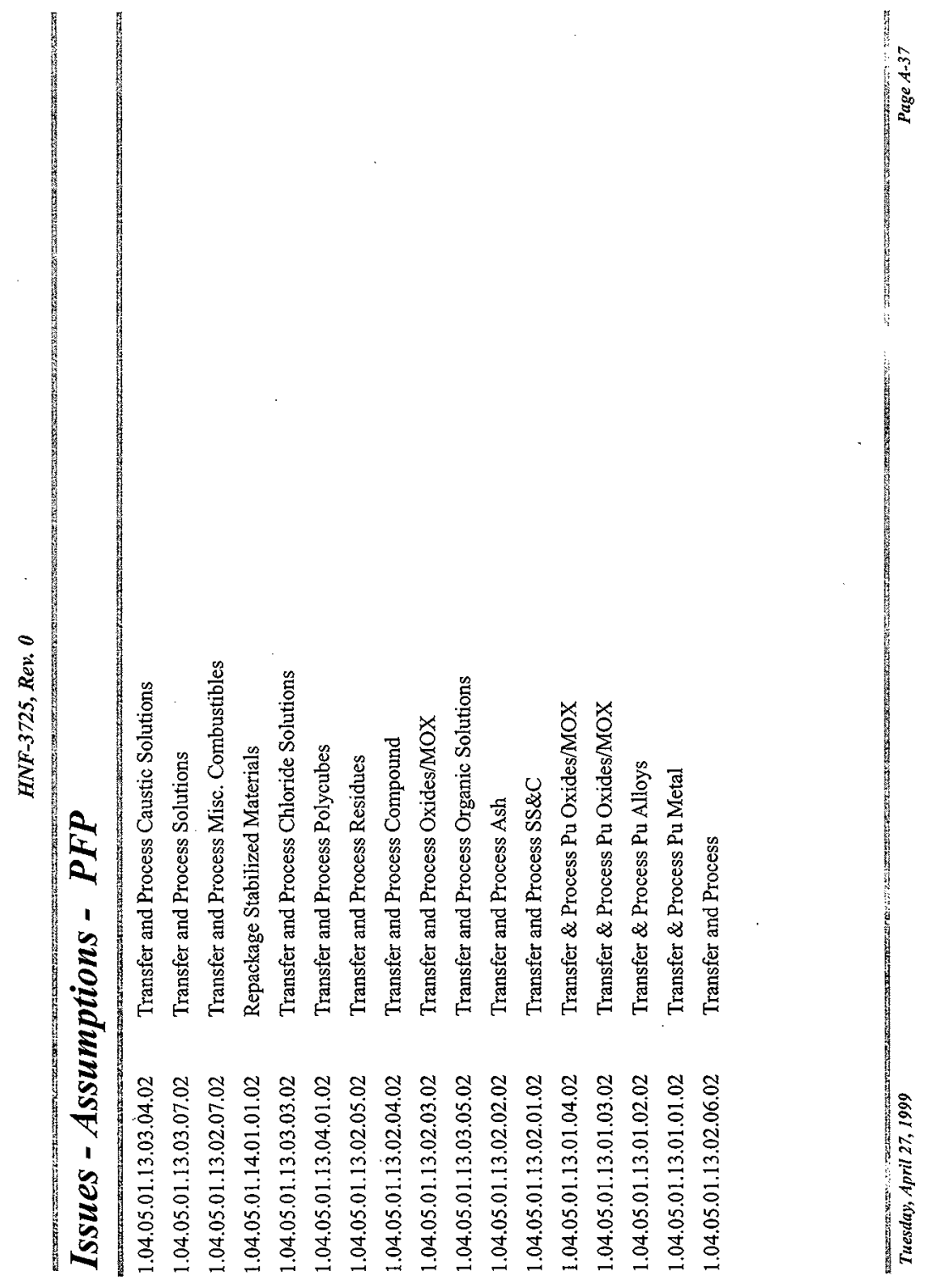




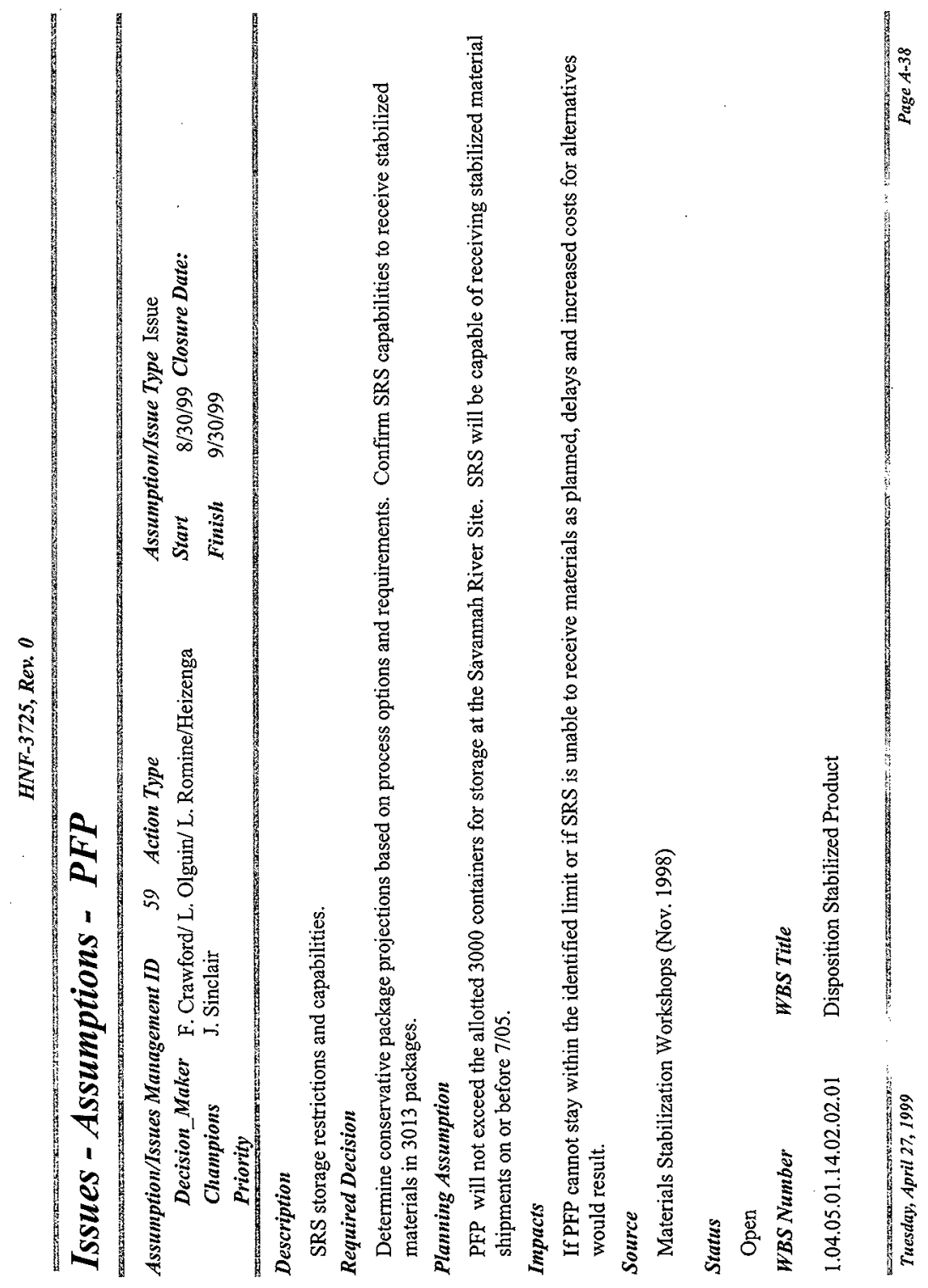




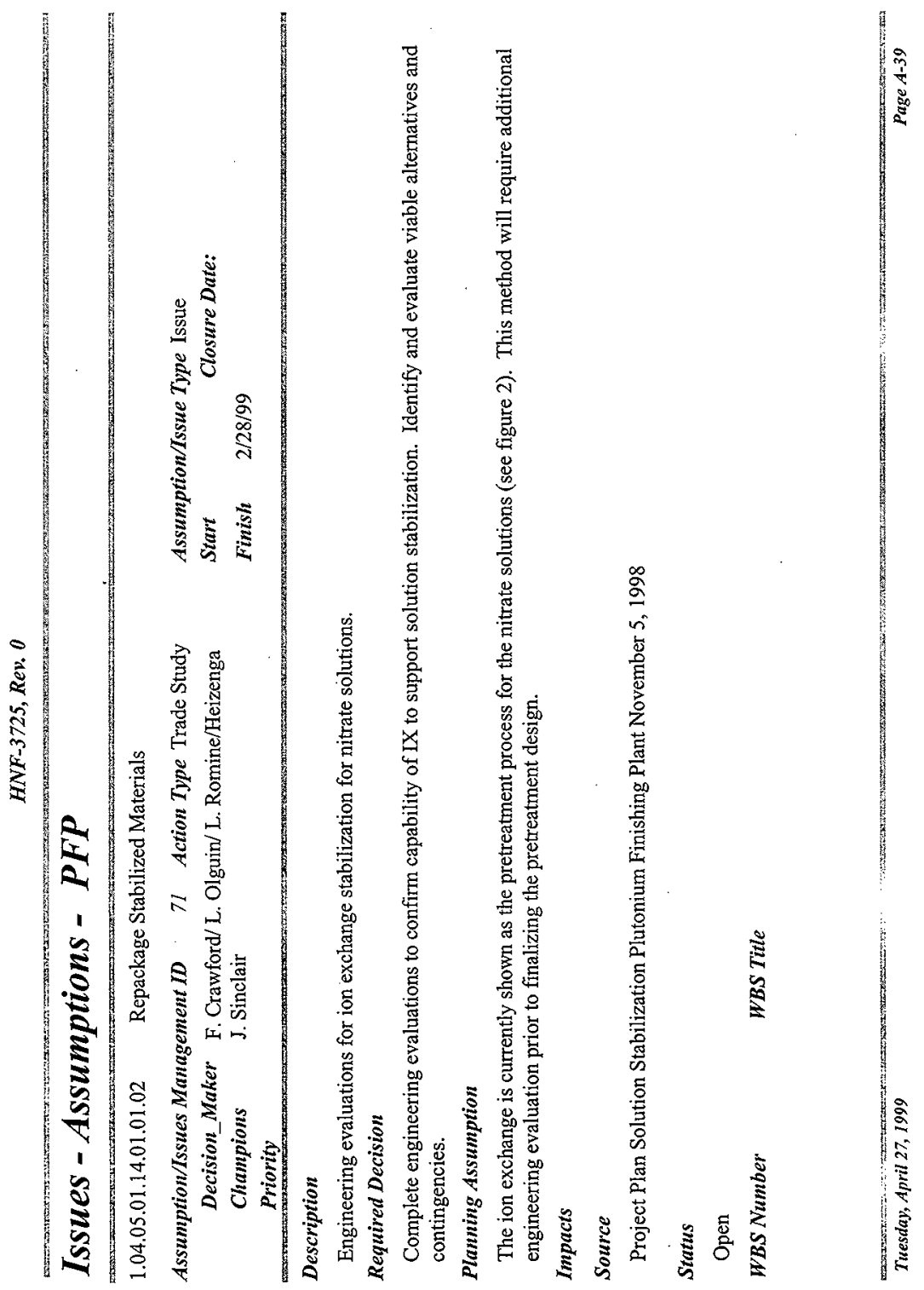




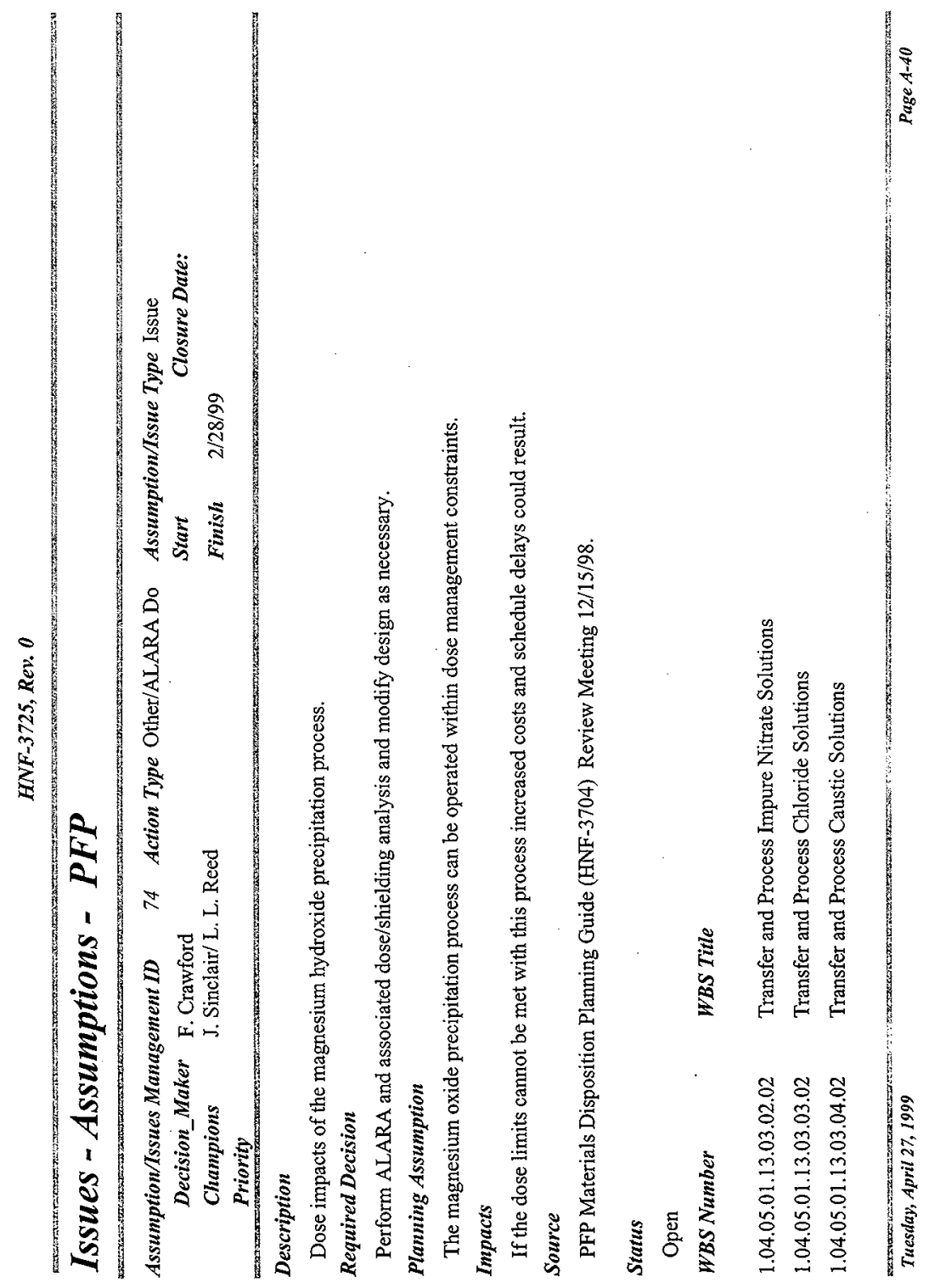




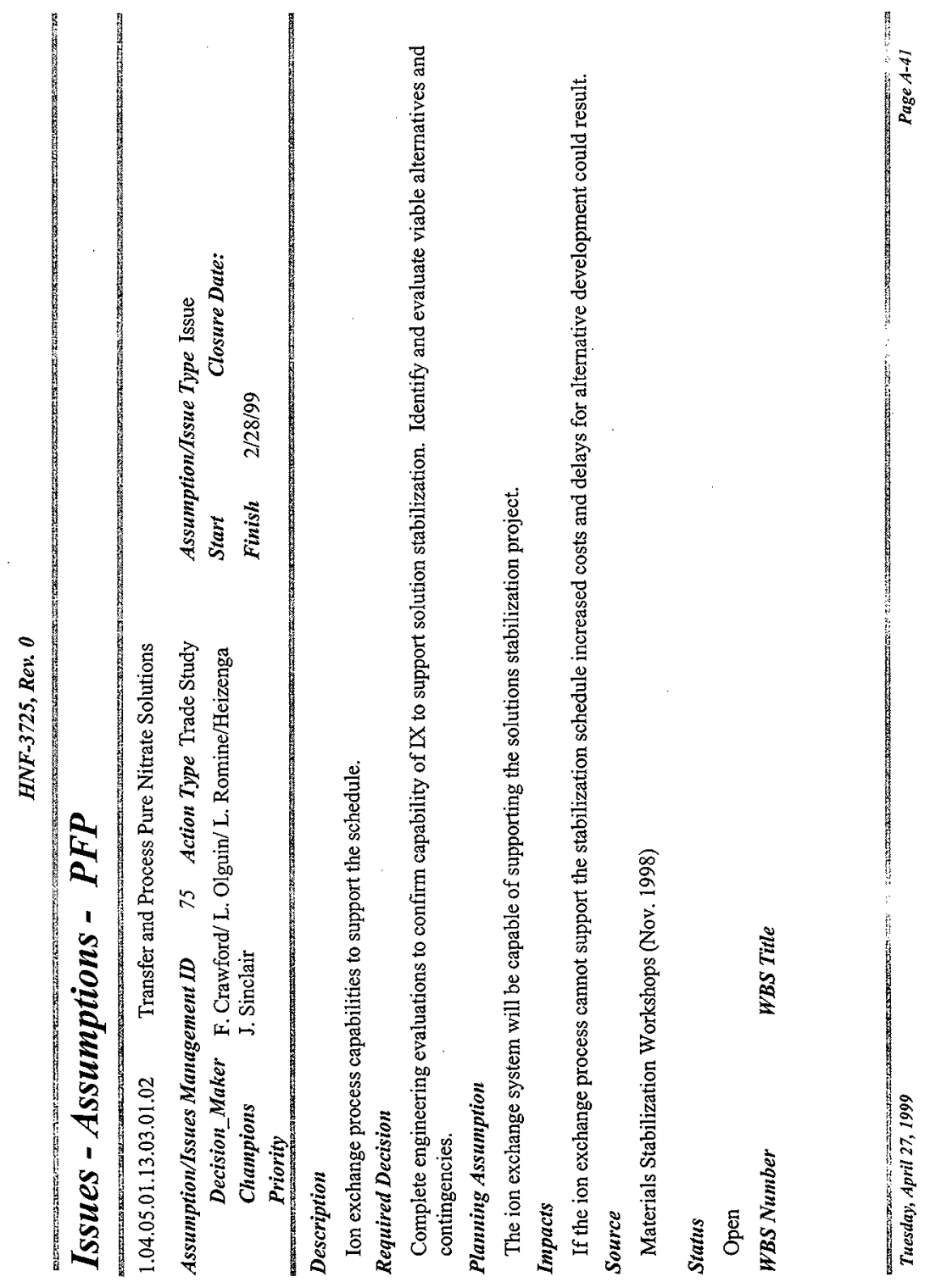




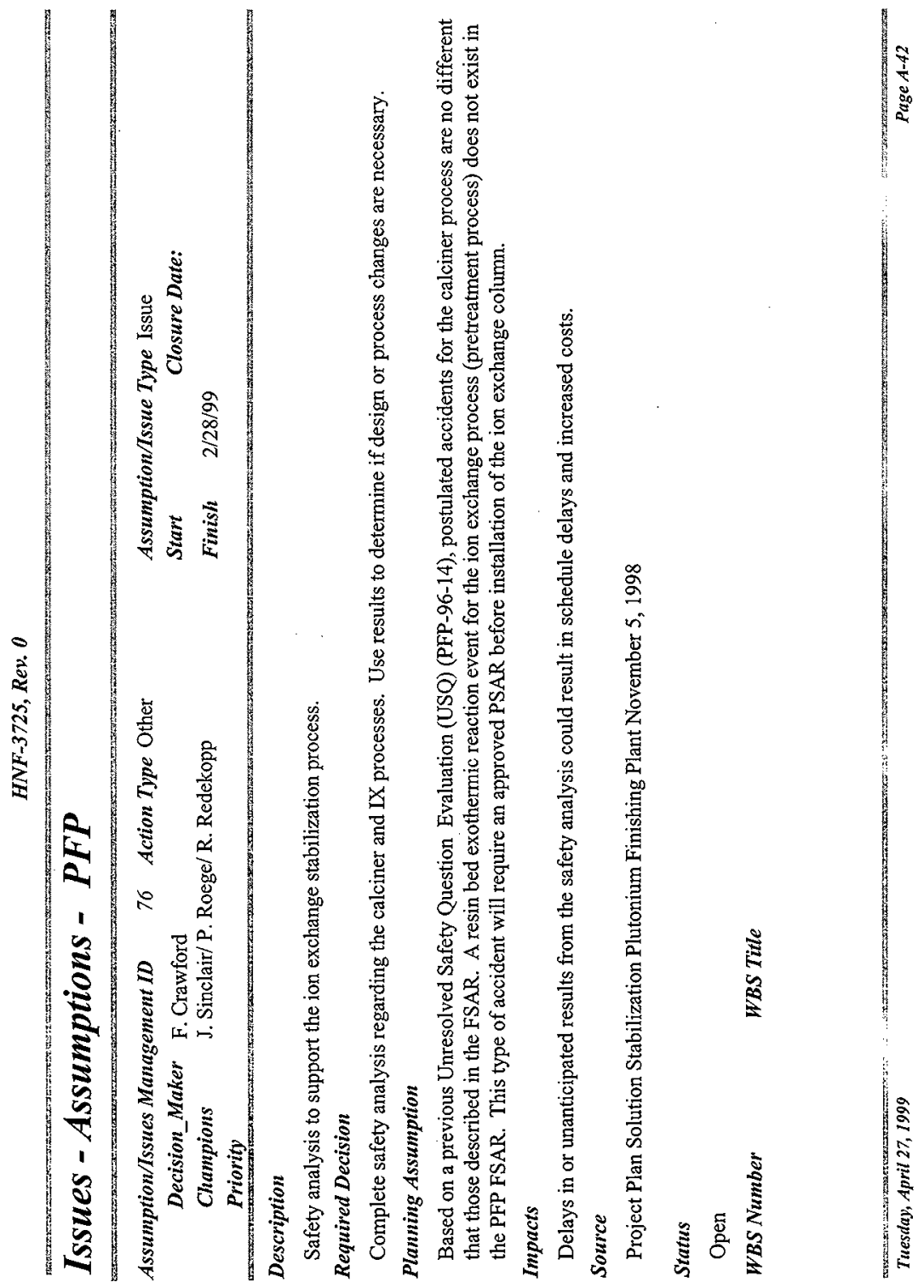




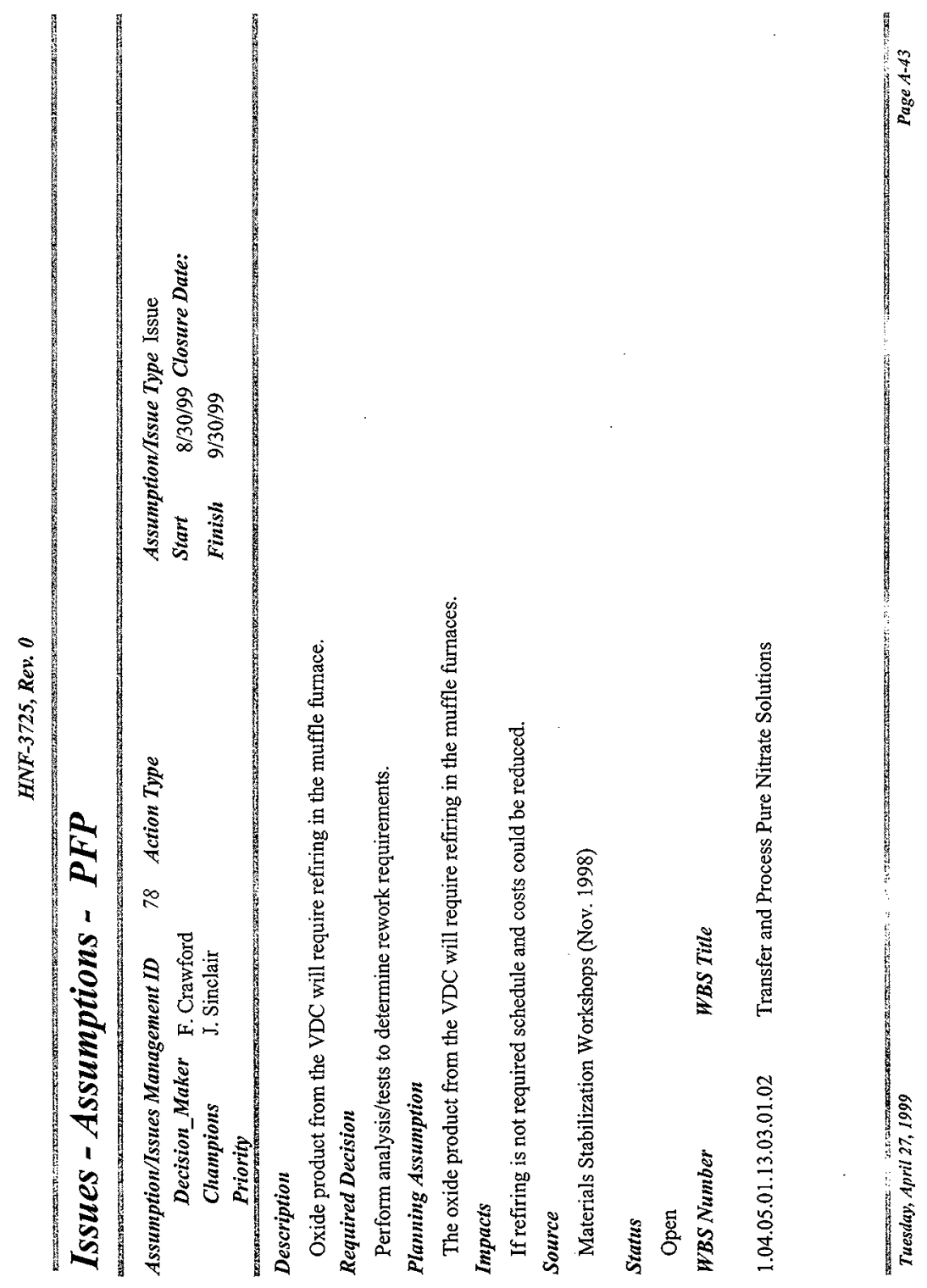




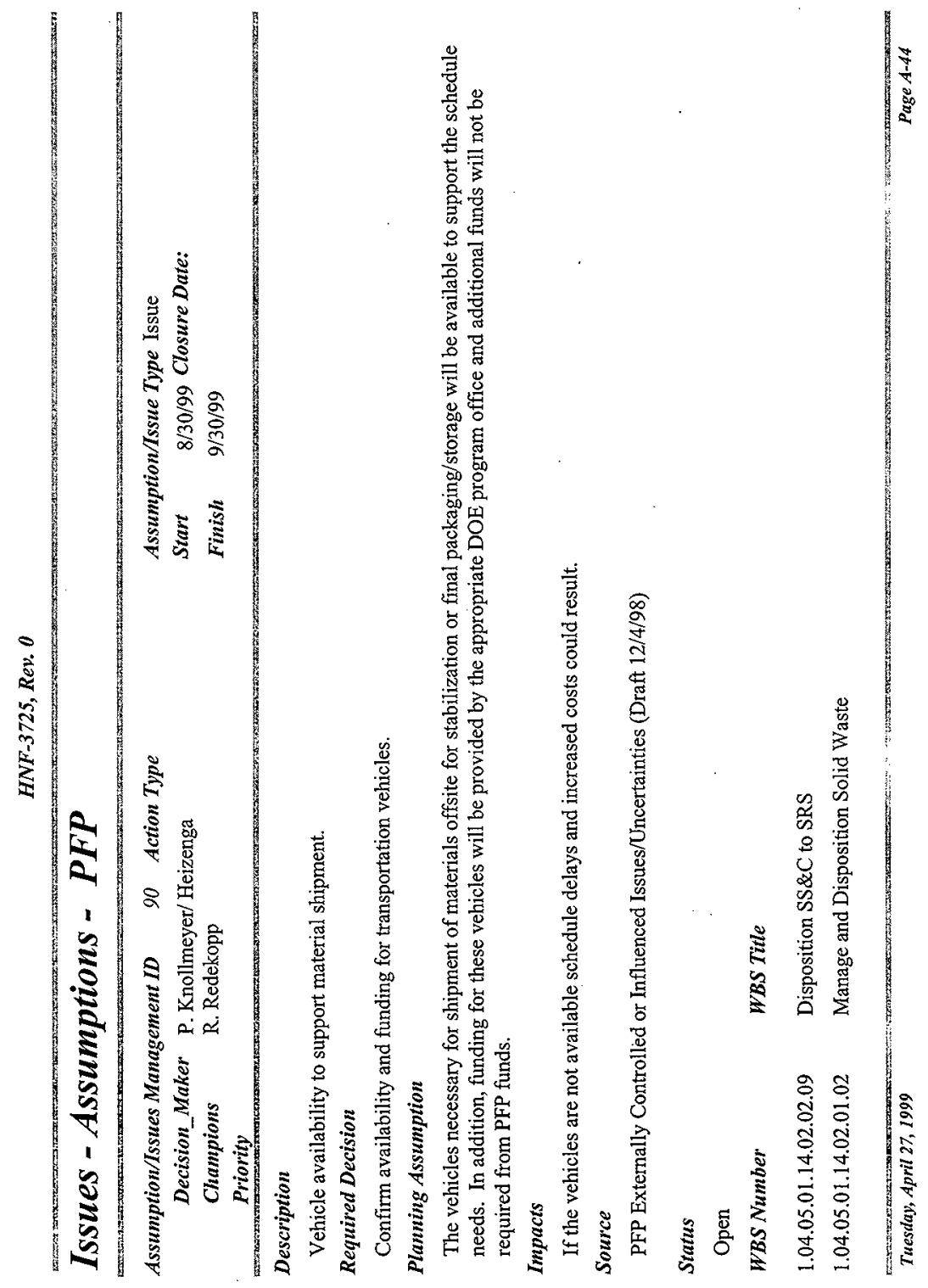




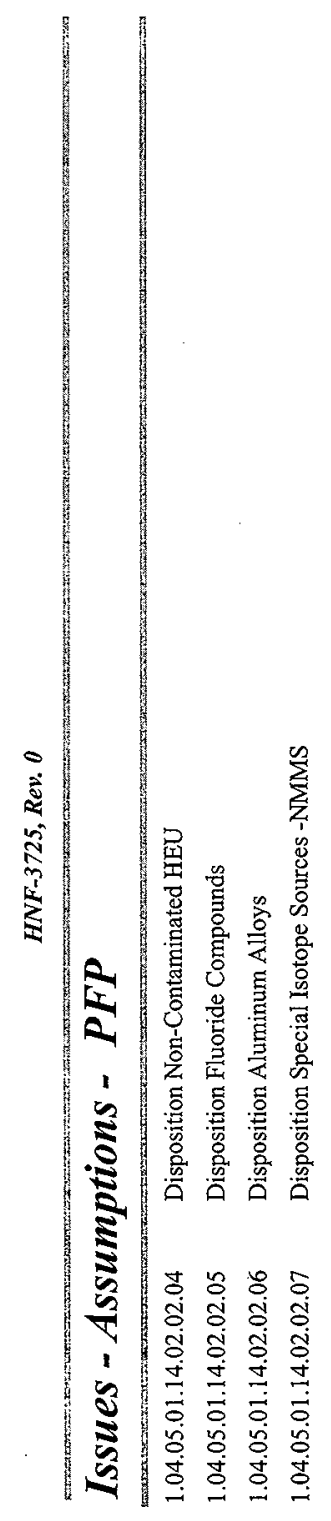


PFP Issues/Assumptions Development and Management Planning Guide

HNF-3725, Rev. 0

Appendix B

Closed Issues and Assumptions Management List 

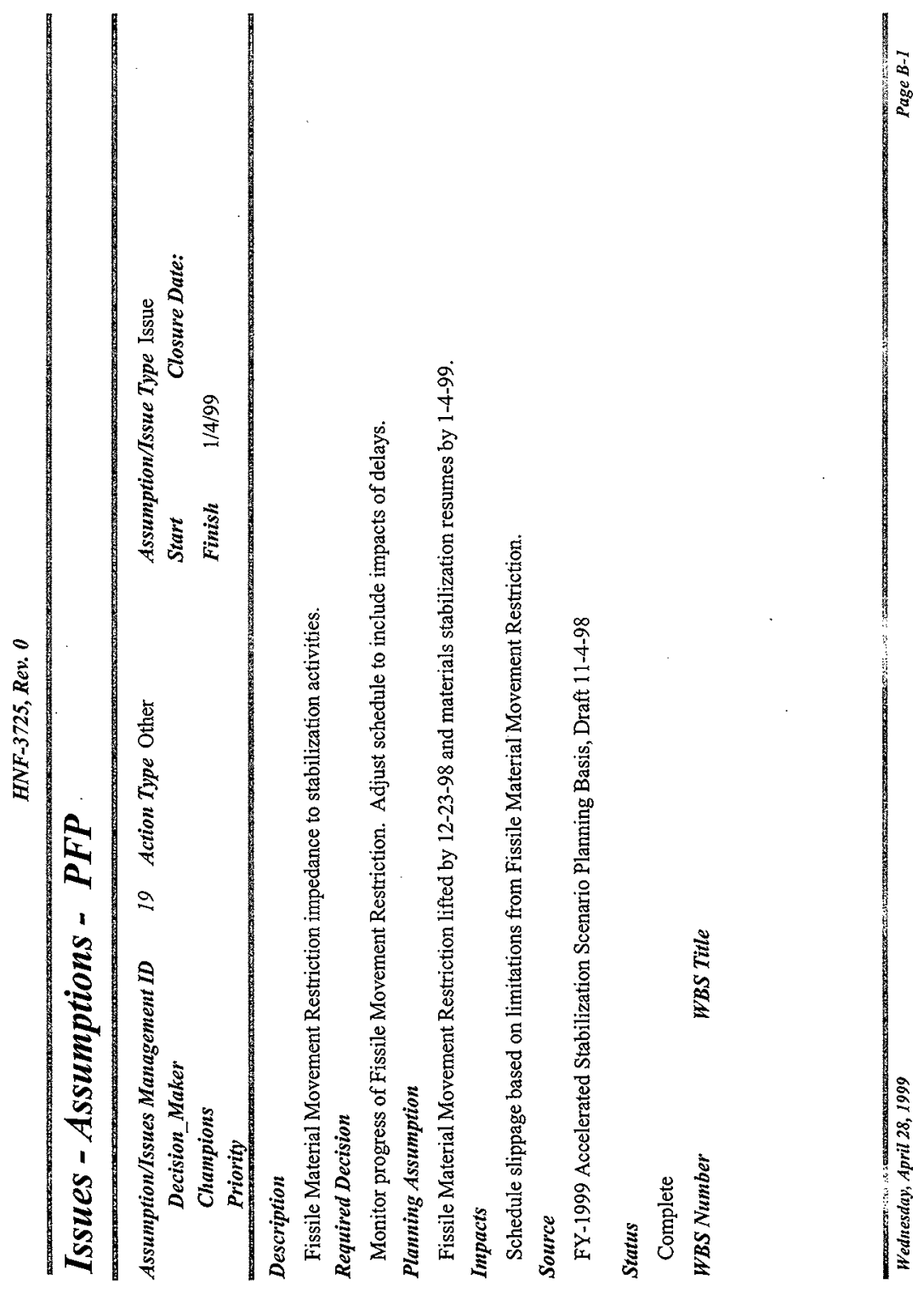